NIST Advanced Manufacturing Series 100-17

\title{
The Influence of Spreading Metal Powders with Different Particle Size Distributions on the Powder Bed Density in Laser-Based Powder Bed Fusion Processes
}

Gregor Jacob Christopher U. Brown Alkan Donmez

This publication is available free of charge from:

https://doi.org/10.6028/NIST.AMS.100-17 
NIST Advanced Manufacturing Series 100-17

\title{
The Influence of Spreading Metal Powders with Different Particle Size Distributions on the Powder Bed Density in Laser-Based Powder Bed Fusion Processes
}

\author{
Gregor Jacob* \\ Christopher U. Brown \\ Alkan Donmez \\ Engineering Laboratory \\ *Currently with Citim GmbH, Barleben, Germany \\ This publication is available free of charge from: \\ https://doi.org/10.6028/NIST.AMS.100-17
}

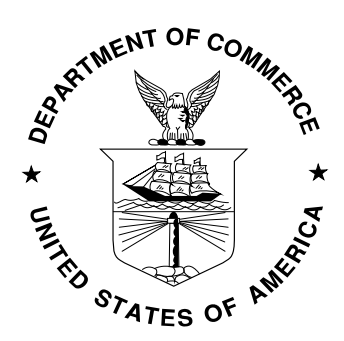

U.S. Department of Commerce Wilbur L. Ross, Jr., Secretary 


\begin{abstract}
In laser powder bed fusion (LPBF) processes, the powder size characteristics, like particle shape, particle size (PS), particle size distribution (PSD), and the resulting powder bed density (PBD), are key influencing factors of the built material properties. To better understand the correlations between the powder size characteristics and the powder properties influencing the LPBF process, apparent density (AD), flowability, and PBD were measured corresponding to two commercial metal powders with different PS and PSD. The powder samples were taken from different locations on the build platform to also investigate the variations of these powder characteristics resulting from the spreading process by the stiff recoater blade. It was shown that the PS and PSD had a significant effect on the AD and the PBD. Powders with a wide PSD and with particle sizes in the range of the effective powder layer thickness, led to a higher PBD than powder with a high proportion of finer particles. No significant differences in PS and PSD were observed as powder was pushed across a build plate by the recoater blade.
\end{abstract}

\title{
Key words
}

additive manufacturing; apparent density; metal powder; particle size distribution; powder bed density; powder bed fusion; powder layer; powder layer thickness; powder spreading; selective laser melting; selective laser sintering. 


\section{Table of Contents}

$\begin{array}{ll}\text { 1. Introduction } & 1\end{array}$

2. Experimental Procedure $\quad 2$

3. Powder Characterization Measurements $\quad 5$

3.1 Powder Sample Preparation 5

3.2 Powder Apparent Density 5

3.3 Powder Bed Density

$\begin{array}{ll}\text { 3.4 Particle Size and Shape Measurement } & 6\end{array}$

$\begin{array}{ll}\text { 4. Results and Discussion } & 7\end{array}$

4.1 Powder Bed Density and Apparent Density 7

4.2 Particle Shape, Size, and Size Distribution 10

4.3 Particle Segregation Behavior During Powder Spreading 18

4.4 Effective Layer Thickness $\quad 21$

$\begin{array}{ll}\text { 5. Conclusions } & 23\end{array}$

$\begin{array}{ll}\text { Acknowledgement } & 24\end{array}$

$\begin{array}{lr}\text { References } & 25\end{array}$ 


\section{Introduction}

For laser powder bed fusion (LPBF) systems to improve build performance, consistency, and part quality, it is important to understand how the powder is spread across the build plate creating the powder layer. ${ }^{1}$ Consistent powder layers uniformly spread across the build plate are important to achieve high-quality parts. One way to understand the uniformity of the powder layer is measuring the density of the powder collected in solidified capsules from multiple locations on the build plate [1].

Studies are found in literature investigating the effects of different particle sizes and size distributions on the characteristics of powder layers and the powder bed density, as well as on the mechanical properties of material manufactured by PBF processes [2-9].

Spierings et al. [8] studied the relationship between the particle size distribution (PSD) and the powder layer thickness and the resulting relative powder layer density (PLD). The relative PLD was determined by the amount of thickness shrinkage after melting and solidifying the powder layer. Such shrinkage also causes an increase in effective powder layer thickness in the next layer, which typically stabilizes after about ten layers. They concluded that effective powder layer thickness should be larger than particle size corresponding to the $90^{\text {th }}$ percentile of the powder $\left(\mathrm{D}_{90}\right)$. Furthermore, they concluded that $\mathrm{D}_{90}$ should be about five times larger than the particle size corresponding to the $10^{\text {th }}$ percentile $\left(\mathrm{D}_{10}\right)$, which should not be smaller than $5 \mu \mathrm{m}$ to avoid impacting the flowability.

The relationship between the PSD and the apparent density (AD) for copper-based powder as well as the effect of $\mathrm{AD}$ on the laser sintered material were investigated by Zhu et al. [7]. They increased the relative AD from $25 \%$ to $77 \%$ by mixing different batches of powder to modify the PSD. They also observed a higher density of the laser sintered material when the $\mathrm{AD}$ of the powder mixture increased.

A new method to determine the powder bed density (PBD) in the LPBF process is described in Jacob et al. [1]. The objective of the current study is to use this new PBD measurement method to determine the effect of spreading metal powders on the density and the other size characteristics of the powder deposited on the build platform. Furthermore, the relationship between the AD of the bulk powder and the PBD from the build using the same powder was investigated. The variations of the PBD across the build platform were also quantified.

\footnotetext{
${ }^{1}$ Official contribution of the National Institute of Standards and Technology (NIST); not subject to copyright in the United States. The full descriptions of the procedures used in this paper require the identification of certain commercial products. The inclusion of such information should in no way be construed as indicating that such products are endorsed by NIST or are recommended by NIST or that they are necessarily the best materials, instruments, software or suppliers for the purposes described.
} 


\section{Experimental Procedure}

Two metal powders, stainless steel (S17-42 ${ }^{2}$ ) and nickel alloy (IN625), with different particle sizes and size distributions were chosen. Both powders were nitrogen gas atomized. Table 1 shows the particle sizes of the powders per the powder supplier specification sheets [10,11]. Two builds, each consisting of nine cylindrical capsules, were conducted using each type of powder. Each capsule held the unprocessed loose powder deposited with each layer during the build process, allowing for the post-process analysis of powder characteristics. Figure 1 shows the dimensions of the capsules used for PBD calculations. For the case of IN625, only virgin powder was used for the two builds (Run \#1 and Run \#2). Unused powder remaining in the dispenser bin after Run \#1 was used for Run \#2. Powder remaining on the build platform after Run \#1, however, was removed to a separate container before Run \#2.

For the case of S17-4, virgin powder was used in the first build (Run \#1). Powder on the build platform and in the collector bin after the first build was mixed, sieved with an $80 \mu \mathrm{m}$ mesh sieve, and reused for the next build (Run \#2).

Table 1. Particle sizes of metal powders used in this study.

\begin{tabular}{lll}
\hline Material & $\begin{array}{l}\text { Powder particle size per } \\
\text { specification sheets }\end{array}$ & Powder condition for builds \\
\hline IN 625 & $D_{10}=13.4 \mu \mathrm{m}$ & Run \#1: virgin \\
& $D_{50}=28.4 \mu \mathrm{m}$ & Run \#2: virgin \\
& $D_{90}=43.0 \mu \mathrm{m}$ & \\
\hline S17-4 & $D_{92}=53 \mu \mathrm{m}$ & Run \#1: virgin \\
& & Run \#2: once recycled \\
\hline
\end{tabular}

Each build consisted of nine cylindrical capsules (see Figure 2) deposited on a $25.4 \mathrm{~mm}$ thick steel (AISI 1045) build platform with an area of $250 \mathrm{~mm}$ x $250 \mathrm{~mm}$. The nine capsules were arranged in a three by three pattern, $85 \mathrm{~mm}$ apart. This pattern provides a grouping of capsules with three locations along the direction of the recoater blade motion to quantify the variations (with three repetitions). Each capsule was supported by a $3 \mathrm{~mm}$ high lattice structure. The recoater blade made of high-strength steel was used to spread the powder. As shown in Figure 2 and Figure 3, the recoater blade motion started from the dispenser bin (on the left side), moved to the right collector side, and ended over the collector bin. ${ }^{3}$

\footnotetext{
${ }^{2}$ This material has the chemical composition corresponding to the stainless steel with official designation of UNS S17400. S17-4 implies precipitation hardening, which may or may not be the case for this powder. This shorthand designation is used in this paper following the customary usage in the AM field.

${ }^{3}$ The recoater blade actually moves from right to left to an observer of the machine, however to remain consistent with the $x$ axis in the figures, we describe the recoater blade direction as left to right.
} 

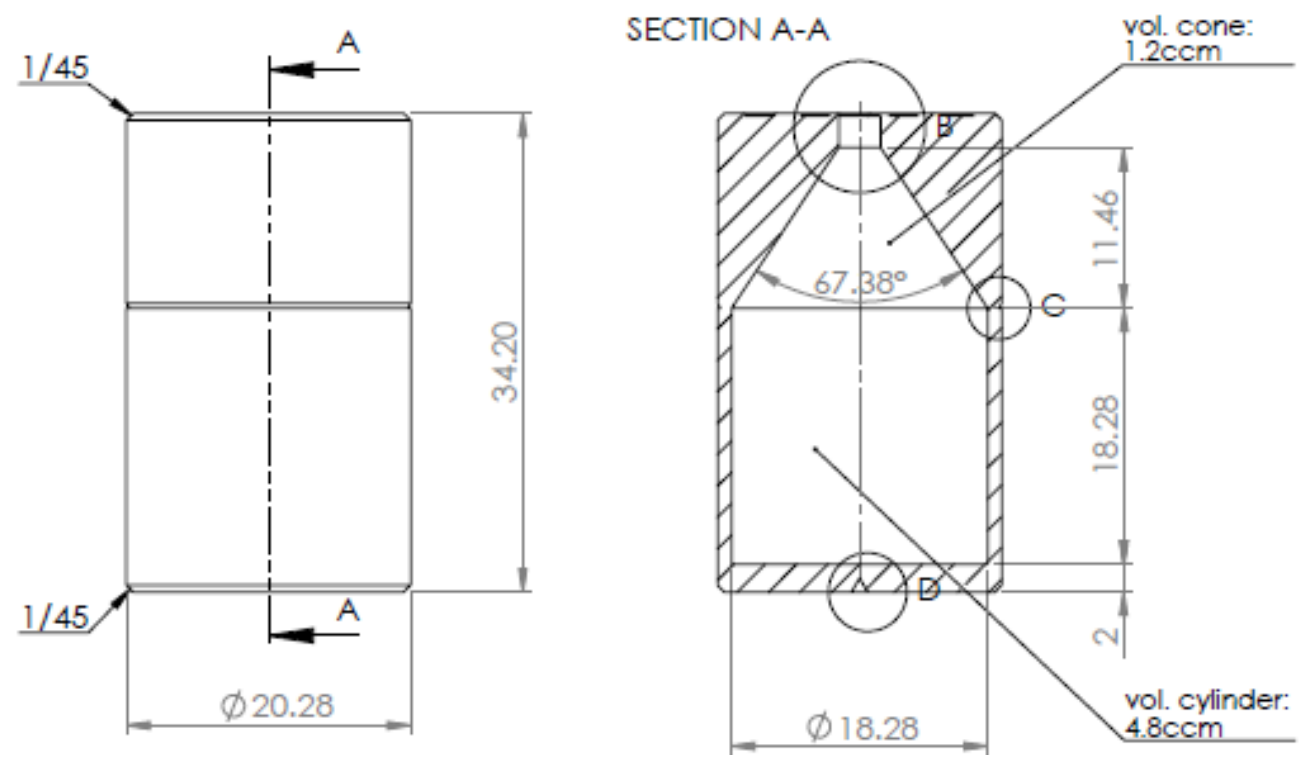

Figure 1. Powder bed density capsules are used to determine the powder bed density directly on the build platform during the manufacturing process, dimensions in millimeters except volume in cubic centimeters.

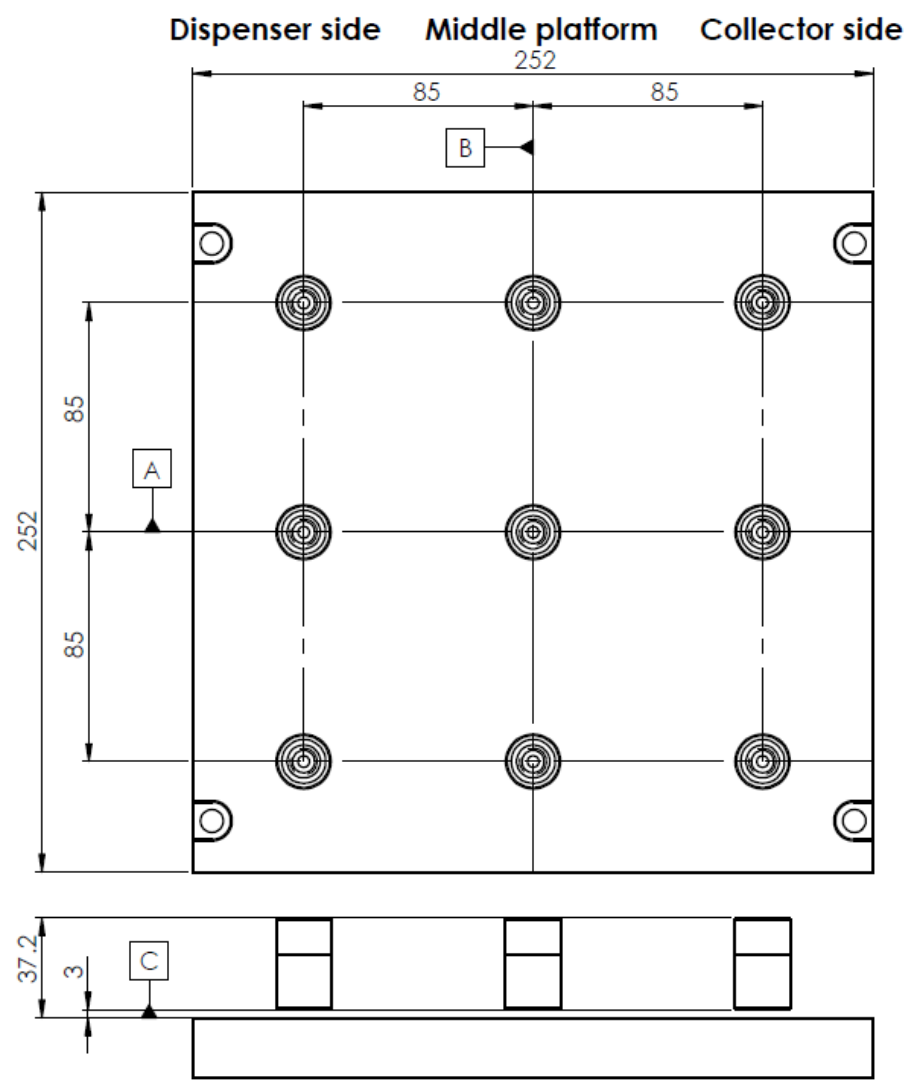

Figure 2. The nine capsule build layout on the build platform. Recoater blade direction parallel to Datum A moving from left to right. Dimensions are in millimeters. 


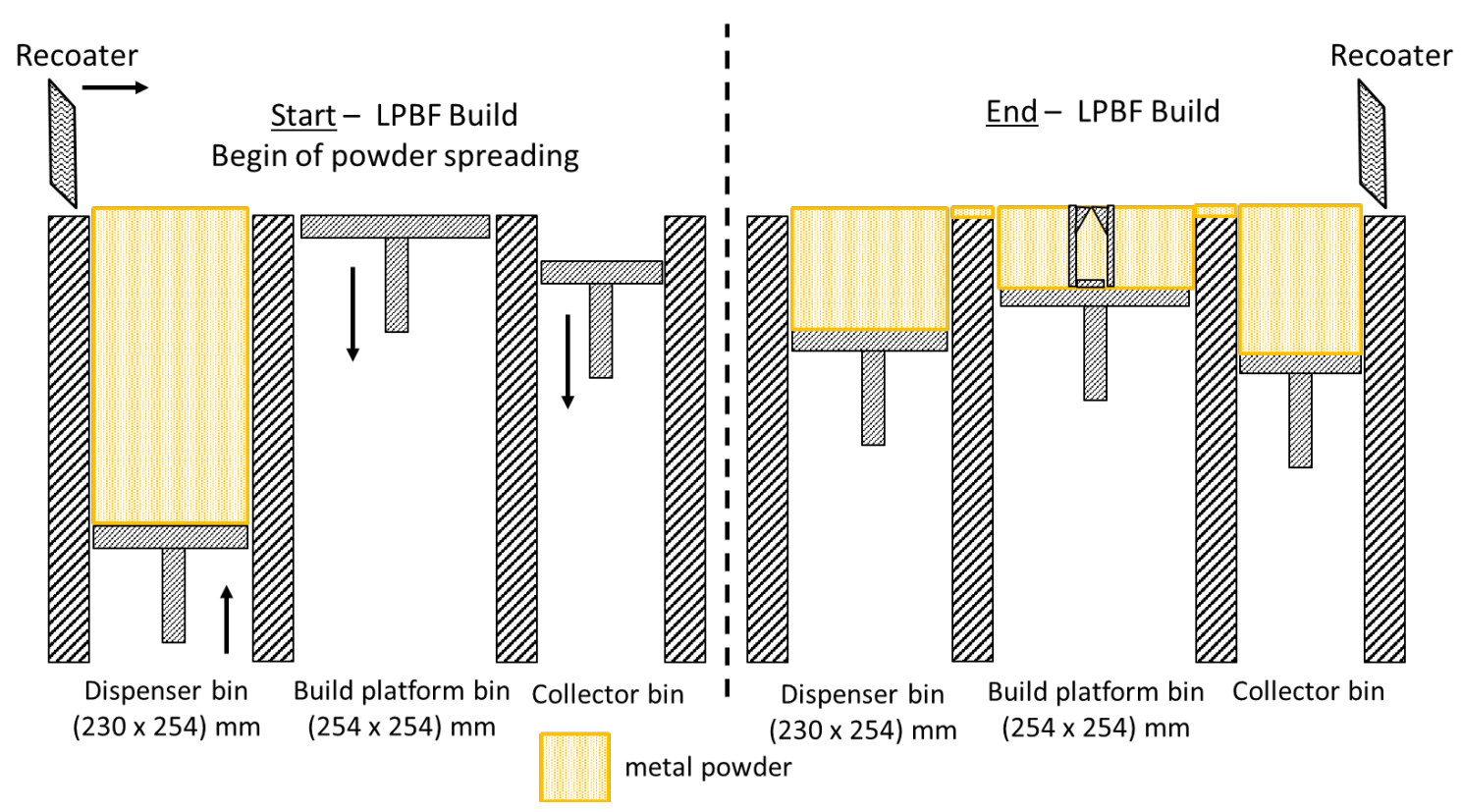

Figure 3. Schematic powder deposition start and ending for an LPBF build. At the end of the build, a hollow cylindrical capsule is manufactured that contains powder.

The nominal build parameter settings used to manufacture PBD capsules from both materials are shown in Table 2. Upon completion of the builds, the contents of the PBD capsules were analyzed to determine changes in powder characteristics resulting from the spreading process. They are also compared to the bulk powder properties obtained from the powder samples collected from the dispenser and collector bins.

Table 2. Build parameter settings for stainless steel (S17-4) and nickel alloy (IN625) PBD capsules.

\begin{tabular}{llll}
\hline & & Material & \\
& S17-4 & IN625 \\
\hline Build chamber atmosphere & Nitrogen & Nitrogen \\
Laser power $[\mathrm{W}]$ & 195 & 195 \\
Laser scan speed $[\mathrm{mm} / \mathrm{s}]$ & 1000 & 850 \\
Laser hatch distance $[\mathrm{mm}]$ & 0.1 & 0.1 \\
Nominal powder layer thickness, $t_{\text {nominal }}$ & 0.02 & 0.02 \\
{$[\mathrm{~mm}]$} & 97.5 & 114.7 \\
Energy Density $\left[\mathrm{J} / \mathrm{mm}^{3}\right]$ & 80 & 80 \\
Pre- heating build platform $\left[{ }^{\circ} \mathrm{C}\right]$ & 80 & 80 \\
Build plate temperature during build $\left[{ }^{\circ} \mathrm{C}\right]$ & 25 \\
Build plate temperature at removal $\left[{ }^{\circ} \mathrm{C}\right]$ & 25 & \\
\hline
\end{tabular}




\section{Powder Characterization Measurements}

\subsection{Powder Sample Preparation}

Powder properties were assessed in terms of morphology, PSD, apparent density (AD), and PBD. Test methods for metal powders require sampling from a bigger quantity. Therefore, the powder samples used to determine the bulk powder properties were taken from the dispenser and collector bins with a slot sampler, homogenized, and riffled to the required representative sample quantity before testing [12].

\subsection{Powder Apparent Density}

Powder sampled from the dispenser bin was used to determine the AD following ASTM B212 [13] using the Hall Flowmeter Funnel (see Figure 4). In general, the AD determined by this method is used to assess the powder bed conditions in the LPBF machine in advance. However, the mechanisms of forming the powder layer inside a LBPF machine are quite different than the mechanisms to obtain the AD of a powder sample in the density cup. The density cup is filled by a freely flowing powder under gravity. In contrast, a powder layer is formed by spreading powder in front of a moving recoater blade over a previously deposited powder layer or solidified part surface. Therefore, the relationship between the AD and the PBD is of interest.

A

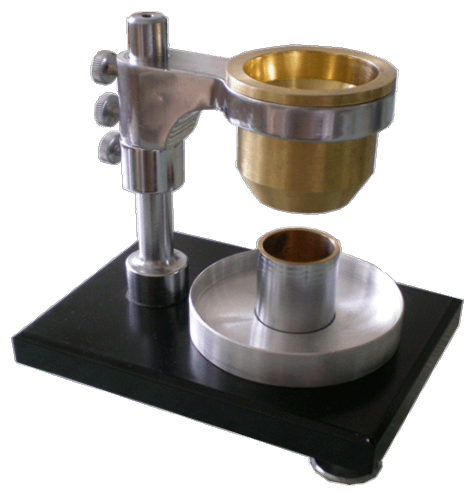

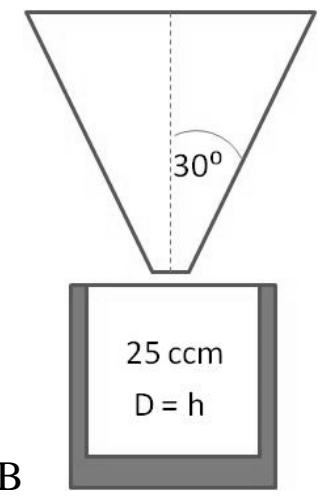

Figure 4. A) Hall Flowmeter Funnel with density cup, and B) schematic drawing, diameter (D), height (h), volume in cubic centimeter (ccm).

\subsection{Powder Bed Density}

PBD is measured using the cylindrical capsules (full of unbound powder captured during the build process) built by the LPBF machine (see Figure 2). After the PBD capsules were built, they were removed from the build plate by wire electrical discharge machining (EDM). The bottom surface of all PBD capsules was ground to obtain a smooth solid surface. The mass of the powder removed from the interior volume was measured to calculate the powder bed density [1]. 


\subsection{Particle Size and Shape Measurement}

A dynamic image analysis (DIA) system was used to characterize the morphology (volumetric aspect ratio, a3) of powder samples and the PSD per ISO 13322-2 [14]. The imaging instrument captures dispersed powder particle shadows using two digital cameras with different magnifications while a software program measures and determines the particle sizes and shape distribution. ISO 9276-1 [15] is used for representation of results of particle size analysis.

Figure 5 shows the particle size characteristics used in this study; the minimum particle diameter $\left(\mathrm{x}_{\mathrm{cmin}}\right)$ determined from all maximum chord particle projections $\left(\mathrm{x}_{\mathrm{c}}\right)$, the maximum direct length from all measured Feret diameters ( $\mathrm{x}_{\mathrm{Femax}}$ ), and the Martin diameter ( $\mathrm{x}_{\mathrm{Ma} \text { min }}$ ), computed by dividing the particle projection area in two bisectors.

A

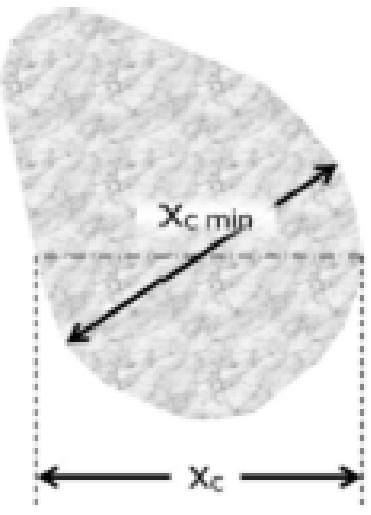

B

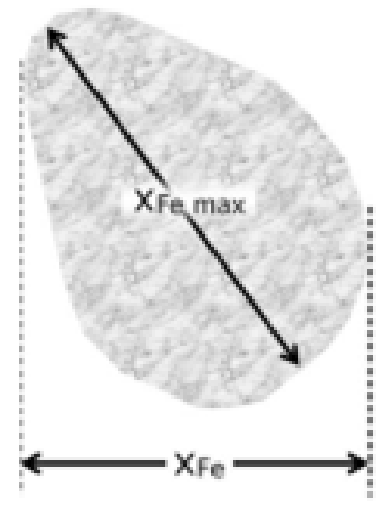

C

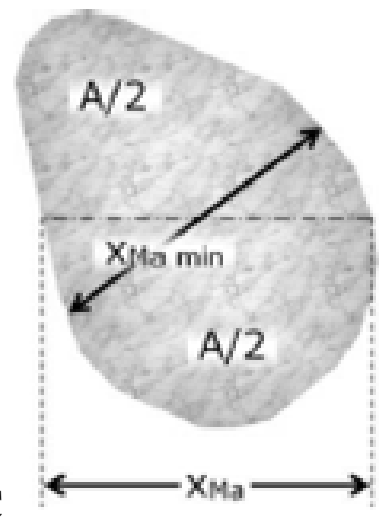

Figure 5. Schematic particle size characteristics $\mathrm{x}_{\mathrm{Cmin}}(\mathrm{A})$, $\mathrm{x}_{\mathrm{Femax}}(\mathrm{B})$, and $\mathrm{x}_{\mathrm{Ma} \text { min }}(\mathrm{C})$ on a particle projection, according to ISO 9276-1 [15].

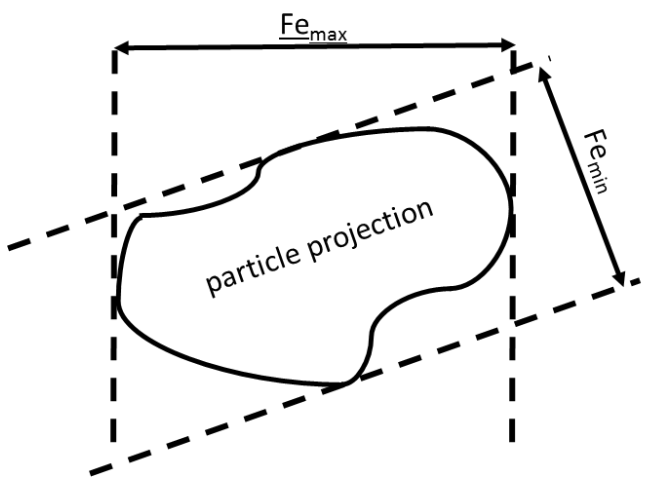

Figure 6: $\mathrm{x}_{\mathrm{Femin}}$ and $\mathrm{x}_{\mathrm{Femax}}$ on particle projection. 
Figure 6 shows the determination of $\mathrm{x}_{\mathrm{Femax}}$ on the particle projection [15]. The volumetric aspect ratio $\left(\mathrm{a}_{3}\right)$ is the ratio of the width $\left(\mathrm{Fe}_{\min }\right)$ over the length $\left(\mathrm{Fe}_{\max }\right)$ of the particle projection. XFemin and $\mathrm{X}_{\mathrm{Femax}}$ are determined by the dynamic imaging system after multiple projections are made from different directions.

A parameter used to quantify the width of the size distribution curve is the SPAN value, defined in Equation 1 [16].

$$
\mathrm{SPAN}=\frac{D_{90}-D_{10}}{D_{50}}
$$

where $\mathrm{D}_{10}, \mathrm{D}_{50}$, and $\mathrm{D}_{90}$ are the cumulative particle diameters at $10 \%, 50 \%$, and $90 \%$ of the entire powder volume.

A smaller SPAN value indicates a narrower particle size distribution or a shift to coarser particle sizes within the same particle size distribution (when the differences between $\mathrm{D}_{90}$ and $\mathrm{D}_{10}$ stays constant and $\mathrm{D}_{50}$ increases).

For the size and aspect ratio calculations, powder locations along the recoater blade direction (x direction) were tested separately while powder locations from front to back in the build chamber (y direction) were combined. The powder samples therefore originated from five locations; the dispenser bin, build locations 1,2 , and 3 , and the collector bin. From each of these locations in the build chamber, three separate powder samples were tested from the combined powder representing each location. Six repeated measurements were made for each sample using the dynamic imaging system. This resulted in a total of 18 measurements for each powder sample location.

\section{Results and Discussion}

\subsection{Powder Bed Density and Apparent Density}

The calculated PBD and AD values for all the IN625 powder samples are shown in Figure 7. This figure and Table 3 show the mean values for each run and the variations corresponding to the build platform locations. The PBD of the IN625 powder decreases slightly as the powder is spread further along with the recoater blade motion (open circles and squares in Figure 7, values from Table 3). The AD for the virgin IN625 powder taken from the dispenser bin before run \#1 was $4.71 \mathrm{~g} / \mathrm{cm}^{3}$ (open diamond in Figure 7), which is similar to the two mean PBD values of samples from run \#1 (4.696 g/ $\mathrm{cm}^{3}$ ) and run \#2 (4.722 g/ $\mathrm{cm}^{3}$ ) (closed circle and square in Figure 7, and mean values in Table 3). The measured $\mathrm{AD}$ is about $56 \%$ of the bulk material density $\left(8.4 \mathrm{~g} / \mathrm{cm}^{3}\right)$ provided by the material vendor [10]. The PBD/AD ratios are 0.997 and 1.003 for build run \#1 and run \#2, respectively (0.6 \% change) (closed and open triangles in Figure 7 ). 


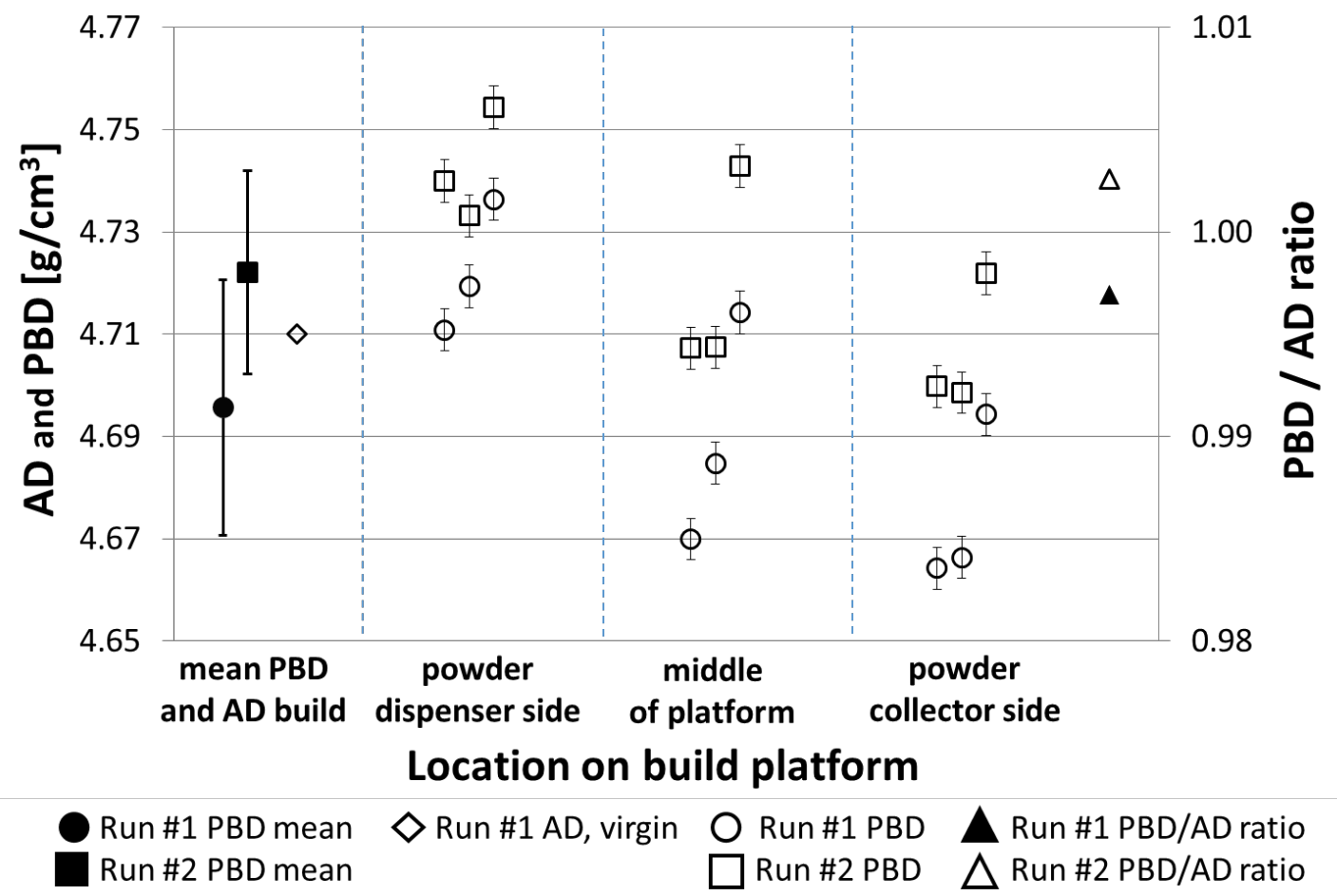

Figure 7. Measured $\mathrm{AD}$ and $\mathrm{PBD}$ with $\mathrm{PBD} / \mathrm{AD}$ ratio of IN625 in virgin condition, error bars are combined uncertainty $\mathrm{U}_{\mathrm{PBD}}$ and one standard deviation (SDEV.S) for the mean.

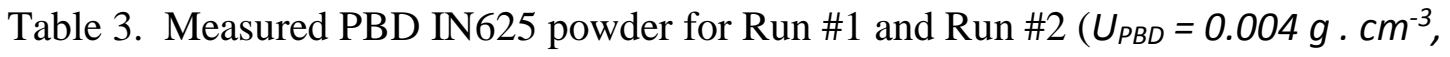
$k=2[1])$

\begin{tabular}{lll}
\hline & Run \#1 & Run \#2 \\
\hline & $P B D$ & $P B D$ \\
PBD-capsule \# & {$\left[\mathrm{g} \cdot \mathrm{cm}^{-3}\right]$} & {$\left[\mathrm{g} \cdot \mathrm{cm}^{-3}\right]$} \\
\hline 1.1 & 4.711 & 4.740 \\
1.2 & 4.719 & 4.733 \\
1.3 & 4.736 & 4.754 \\
\hline 2.1 & 4.700 & 4.707 \\
2.2 & 4.685 & 4.707 \\
2.3 & 4.714 & 4.743 \\
\hline 3.1 & 4.664 & 4.700 \\
3.2 & 4.666 & 4.699 \\
3.3 & 4.694 & 4.722 \\
\hline Mean & 4.696 & 4.722 \\
\hline SDEV.S & 0.025 & 0.020 \\
\hline
\end{tabular}


The similar results for S17-4 powder are shown in Figure 8 and Table 4. The AD of the virgin S17-4 powder taken from the dispenser bin before build run \#1 was $3.85 \mathrm{~g} / \mathrm{cm}^{3}$ and before build run \#2 (once recycled) was $3.92 \mathrm{~g} / \mathrm{cm}^{3}$ (not shown in Figure 8 due to scale). The mean PBD values were $4.677 \mathrm{~g} / \mathrm{cm}^{3}$ and $4.694 \mathrm{~g} / \mathrm{cm}^{3}$ for run \#1 and run \#2, respectively (closed circle and square in Figure 8, and mean values in Table 4). The $\mathrm{PBD} / \mathrm{AD}$ ratios were 1.215 and 1.198 for run $\# 1$ and run \#2, respectively (closed and opened triangles in Figure 8). It is noted that most of this change is due to the change in the $\mathrm{AD}$ between the two runs $(1.8 \%)$ rather than the change in the PBD $(0.4 \%)$.

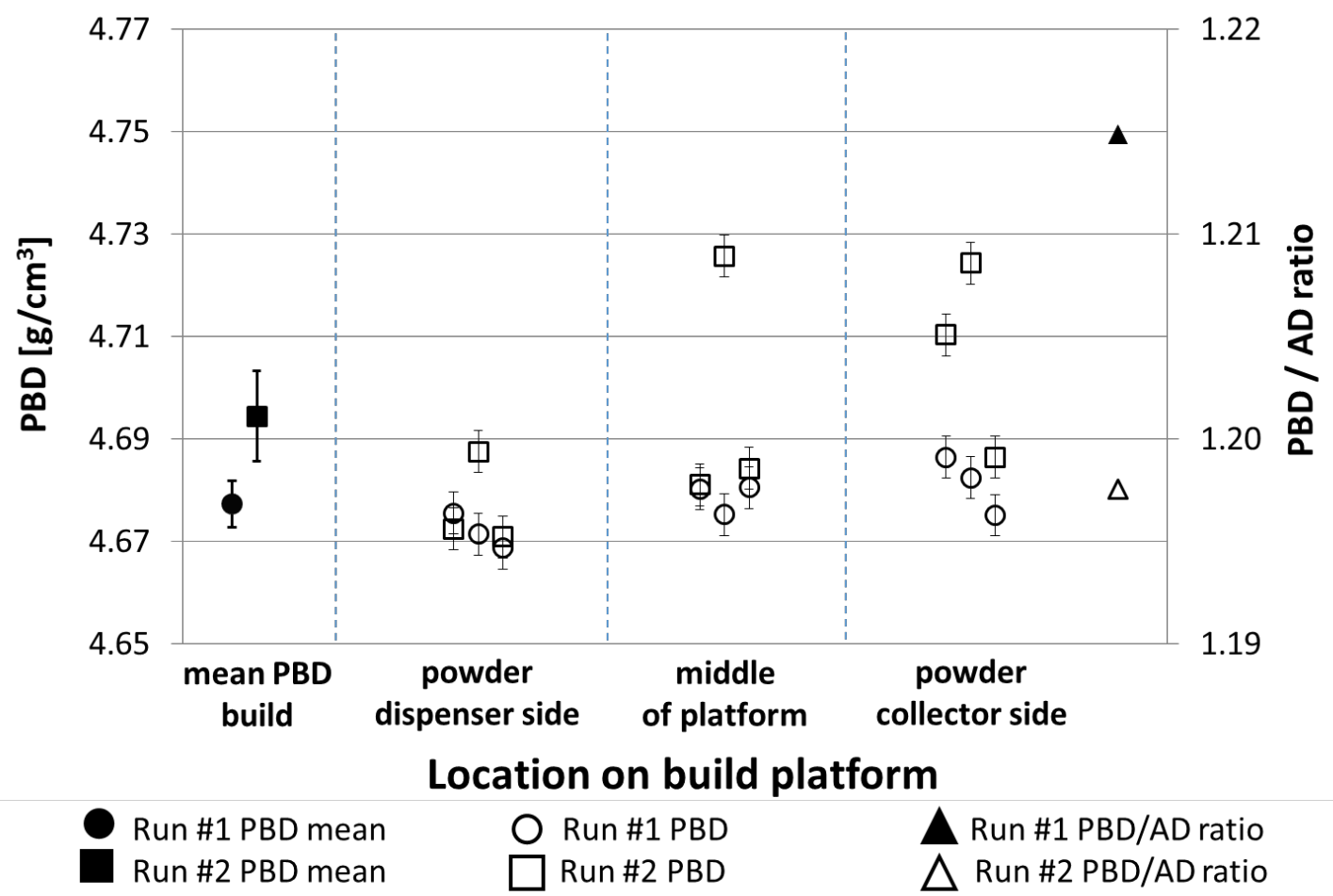

Figure 8. PBD with $\mathrm{PBD} / \mathrm{AD}$ ratio on S17-4 stainless steel in virgin and one time recycled condition, error bars are combined uncertainty $U_{P B D}$. 
Table 4. Measured PBD of S17-4 powder for Run \#1 and Run \#2 $\left(U_{P B D}=0.004 \mathrm{~g} . \mathrm{cm}^{-3}\right.$, $k=2[1])$.

\begin{tabular}{lll}
\hline Powder condition & $\begin{array}{l}\text { Run \#1 } \\
\text { virgin }\end{array}$ & $\begin{array}{l}\text { Run \#2 } \\
\text { once recycled } \\
\text { PBD } \\
{\left[\mathrm{g} \cdot \mathrm{cm}^{-3}\right]}\end{array}$ \\
\hline PBD- capsule \# & 4.675 & {$\left[\mathrm{~g} \cdot \mathrm{cm}^{-3}\right]$} \\
\hline 1.1 & 4.671 & 4.672 \\
1.2 & 4.669 & 4.687 \\
1.3 & 4.680 & 4.671 \\
\hline 2.1 & 4.675 & 4.681 \\
2.2 & 4.681 & 4.726 \\
2.3 & 4.686 & 4.684 \\
\hline 3.1 & 4.682 & 4.710 \\
3.2 & 4.675 & 4.724 \\
3.3 & 4.677 & 4.686 \\
\hline Mean & 0.005 & 4.694 \\
\hline SDEV.S & & 0.020 \\
\hline
\end{tabular}

Similar results of the PBD/AD ratios of S17-4 powder ranging between 1.05 and 1.12 were observed by Jacob et al. [17]. Hence, the deposition of metal powders in $20 \mu \mathrm{m}$ thick layers leads to a PBD very close to the AD of the bulk powder measured with the Hall funnel flowmeter [13]. Previously, Liu et al. [9] showed that the Hausner ratio, which is the ratio of tapped density of powder to its freely settled density, was a good predictor of PBD in a PBF machine.

In contrast to the results of IN625 powder where the PBD slightly decreases along the recoater blade direction, Figure 8 (open circles and squares) shows the PBD of the S17-4 powder increasing slightly as the powder is spread further along with the recoater blade motion (the difference between the PBD on the dispenser and collector side on the build platform is less than $1.5 \%$ ). This is surprising because we expected the PBD of the S174 powder to also decrease along the recoater blade direction. These observations led to the investigation of the particle size and PSD of the powder captured in the PBD capsules from different locations on the build platform.

\subsection{Particle Shape, Size, and Size Distribution}

Morphologies of IN625 and S17-4 powders were analyzed using the dynamic imaging system by determining the volumetric aspect ratios $\left(\mathrm{a}_{3}\right)$ of powder particles sampled from the PBD capsules. The aspect ratio for all particles with sizes up to $40 \mu \mathrm{m}$, regardless of the build platform location, was close to 0.85 , which indicates a nearly spherical shape. However, for particle sizes larger than $50 \mu \mathrm{m}$, the aspect ratios vary significantly, likely due to particles mostly composed of joined smaller particles that exhibit irregular morphology (see Figures 9 and 10). As shown in Table 1, $90 \%$ of the IN625 powder 
was smaller than or equal to $43 \mu \mathrm{m}$, and $92 \%$ of the S17-4 was smaller than or equal to $53 \mu \mathrm{m}$. Therefore, the data suggests that powder spreading by the recoater blade does not cause significant segregation by particle shape.

The measured particle size cumulative distribution $\left(\mathrm{Q}_{3}\right)$ in terms of $\mathrm{x}_{\mathrm{cmin}}, \mathrm{x}_{\mathrm{Femax}}$, and $\mathrm{x}_{\mathrm{Ma}}$ from virgin IN625 powder sampled from the dispenser bin are shown in Figure 11 . The shift in the curves among $\mathrm{x}_{\mathrm{cmin}}, \mathrm{X}_{\mathrm{Femax}}$, and $\mathrm{x}_{\mathrm{Ma}}$ is the result of the differences among the standard methods used to measure these size characteristics. Figure 11 also shows the particle size frequency distribution $\left(\mathrm{q}_{3}\right)$ of $\mathrm{x}_{\mathrm{cmin}}$. The results of the measured particle size frequency distribution $\left(\mathrm{q}_{3}\right)$ show that the largest powder fraction are particles with $\mathrm{x}_{\mathrm{cmin}}$ less than $30 \mu \mathrm{m}$. Results show that the particles bigger than $40 \mu \mathrm{m}$ are less than $5 \%$ of the powder.

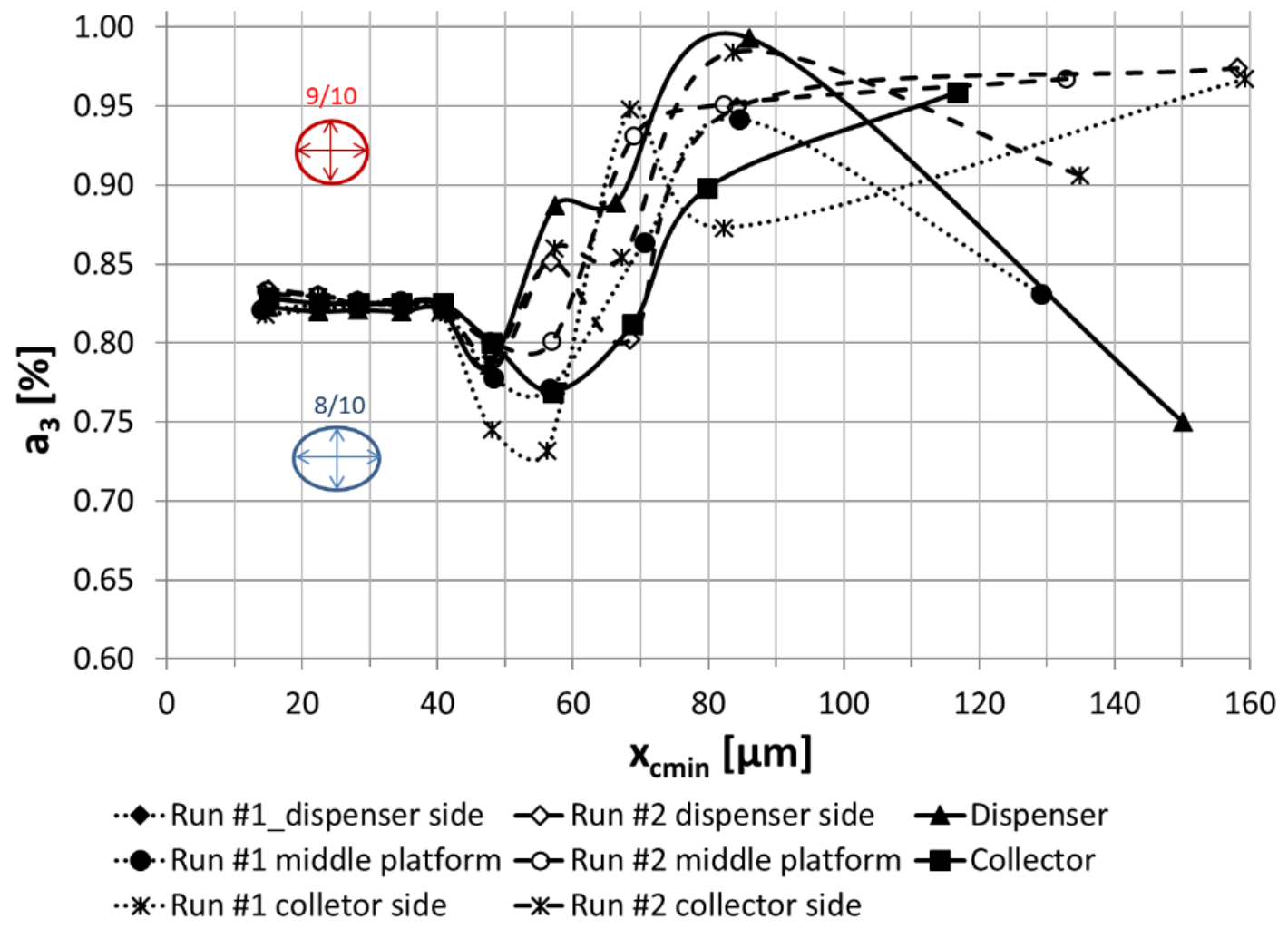

Figure 9. Volumetric aspect ratio $\left(a_{3}\right)$ of IN625 powder from different locations inside the PBF machine along the recoater arm motion. 


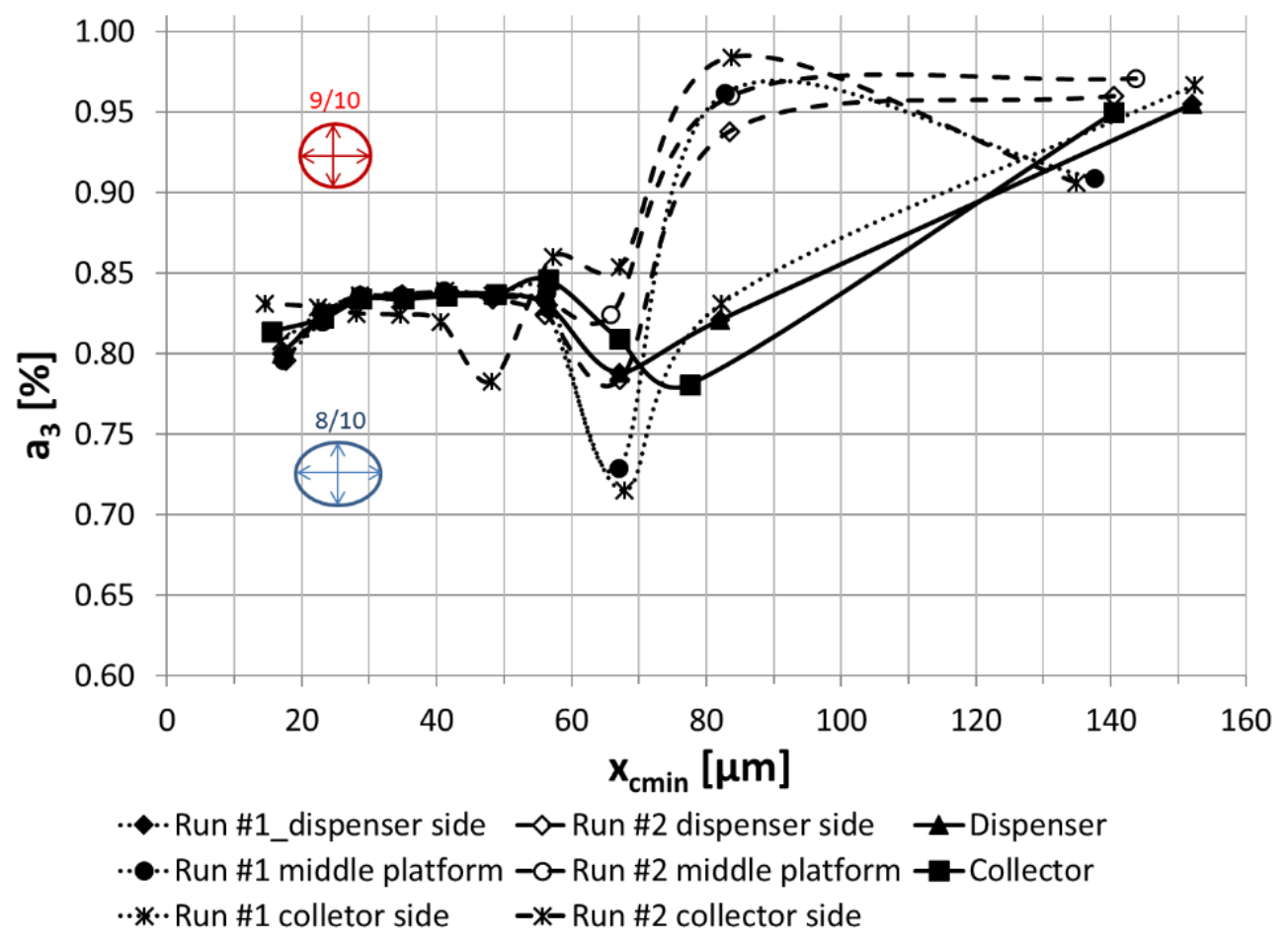

Figure 10. Volumetric aspect ratio $\left(\mathrm{a}_{3}\right)$ of S17-4 powder from different locations inside the PBF machine along the recoater arm motion.

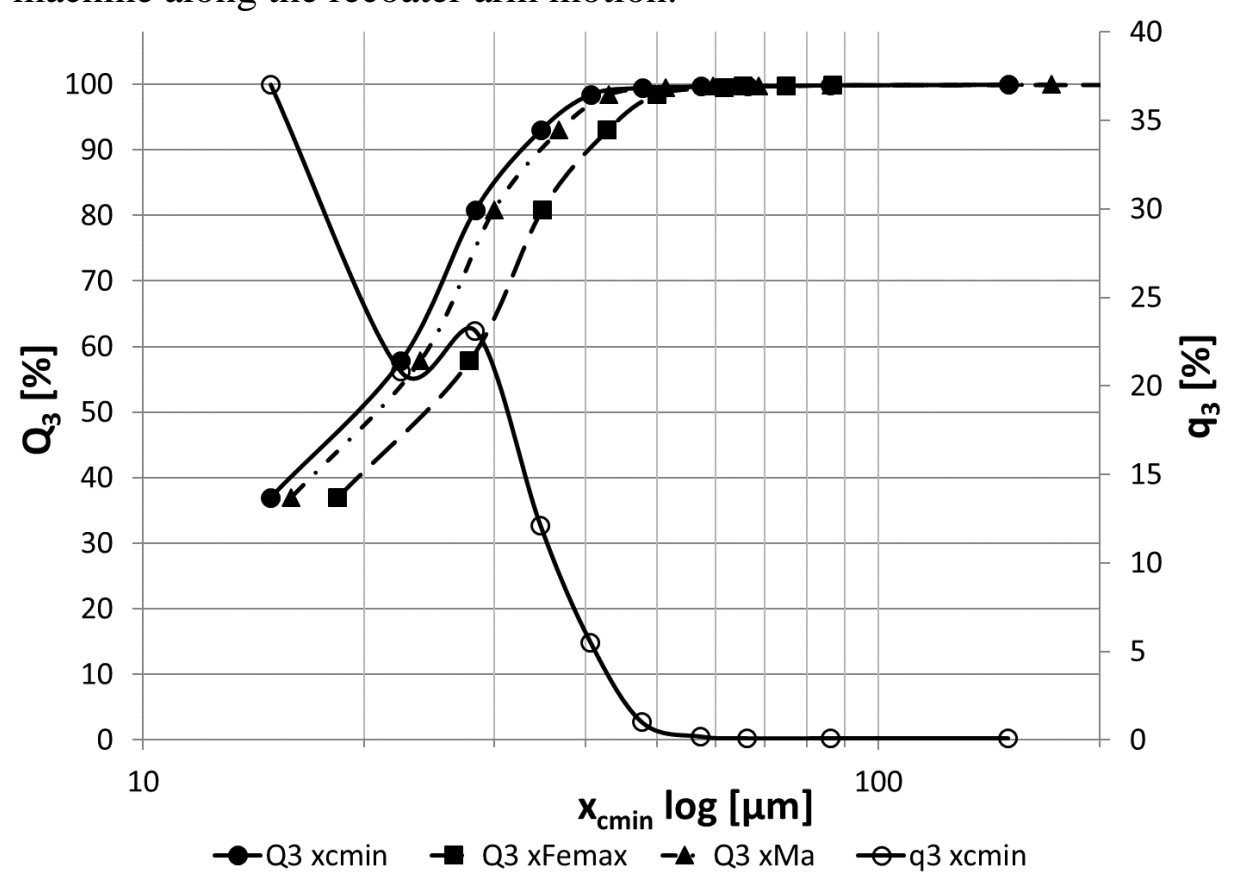

Figure 11. Particle size frequency distribution $\left(\mathrm{q}_{3}\right)$ for $\mathrm{x}_{\mathrm{cmin}}$, and particle size cumulative distribution $\left(\mathrm{Q}_{3}\right)$ for $\mathrm{x}_{\mathrm{Cmin}}, \mathrm{x}_{\mathrm{Femax}}$, and $\mathrm{x}_{\mathrm{Ma}}$ of IN625 (virgin) powder from the dispenser bin. 
Table 5, Figure 12, and Figure 13 present the summary of results of the particle sizes and PSDs of IN625 powder sampled from the dispenser and collector bins as well as from the PBD capsules at different locations on the build platform from both runs \#1 and \#2.

Table 5. Particle sizes $\left(\mathrm{D}_{10}, \mathrm{D}_{50}\right.$, and $\left.\mathrm{D}_{90}\right)$ of IN625 powder samples from different locations along the direction of the recoater blade motion. Average (AVE) and one standard deviation (STDEV.S) values are calculated from a total of 18 measurements (3 powder samples repeatedly measured 6 times).

\begin{tabular}{|c|c|c|c|c|c|c|c|c|}
\hline \multirow[b]{2}{*}{ IN625 powder samples } & \multicolumn{2}{|c|}{$D_{10}$} & \multicolumn{2}{|c|}{$\mathrm{D}_{50}$} & \multicolumn{2}{|c|}{$\mathrm{D}_{90}$} & \multirow{2}{*}{$\begin{array}{l}\text { Ratio } \\
D_{90} / D_{10}\end{array}$} & \multirow[b]{2}{*}{ SPAN } \\
\hline & $\begin{array}{l}\text { AVE } \\
{[\mu \mathrm{m}]}\end{array}$ & $\begin{array}{c}\text { STDEV.S } \\
{[\mu \mathrm{m}]}\end{array}$ & $\begin{array}{l}\text { AVE } \\
{[\mu \mathrm{m}]}\end{array}$ & $\begin{array}{c}\text { STDEV.S } \\
{[\mu \mathrm{m}]}\end{array}$ & $\begin{array}{l}\text { AVE } \\
{[\mu \mathrm{m}]}\end{array}$ & $\begin{array}{c}\text { STDEV.S } \\
{[\mu \mathrm{m}]}\end{array}$ & & \\
\hline \multicolumn{9}{|l|}{ Run \#1 - virgin powder } \\
\hline Dispenser bin & 12.0 & 0.9 & 22.4 & 1.2 & 36.2 & 2.1 & 3.0 & 1.1 \\
\hline Dispenser side (1.x) & 11.0 & 0.7 & 21.1 & 0.9 & 34.6 & 1.1 & 3.2 & 1.1 \\
\hline Middle platform (2.x) & 11.8 & 0.8 & 22.2 & 1.0 & 36.3 & 0.9 & 3.0 & 1.1 \\
\hline Collector side (3.x) & 12.8 & 0.6 & 23.3 & 0.6 & 36.3 & 0.9 & 2.9 & 1.0 \\
\hline Collector bin & 14.4 & 0.5 & 26.2 & 0.4 & 38.8 & 0.7 & 2.7 & 0.9 \\
\hline \multicolumn{9}{|l|}{ Run \#2 - virgin powder } \\
\hline Dispenser side (1.x) & 11.8 & 0.7 & 21.8 & 0.9 & 34.9 & 0.8 & 3.0 & 1.1 \\
\hline Middle platform (2.x) & 11.6 & 0.3 & 22.0 & 0.4 & 35.6 & 0.5 & 3.1 & 1.1 \\
\hline Collector side (3.x) & 13.1 & 1.0 & 23.6 & 1.9 & 36.4 & 1.2 & 2.8 & 1.0 \\
\hline Collector bin & 14.4 & 0.5 & 26.2 & 0.4 & 38.8 & 0.7 & 2.7 & 0.9 \\
\hline
\end{tabular}




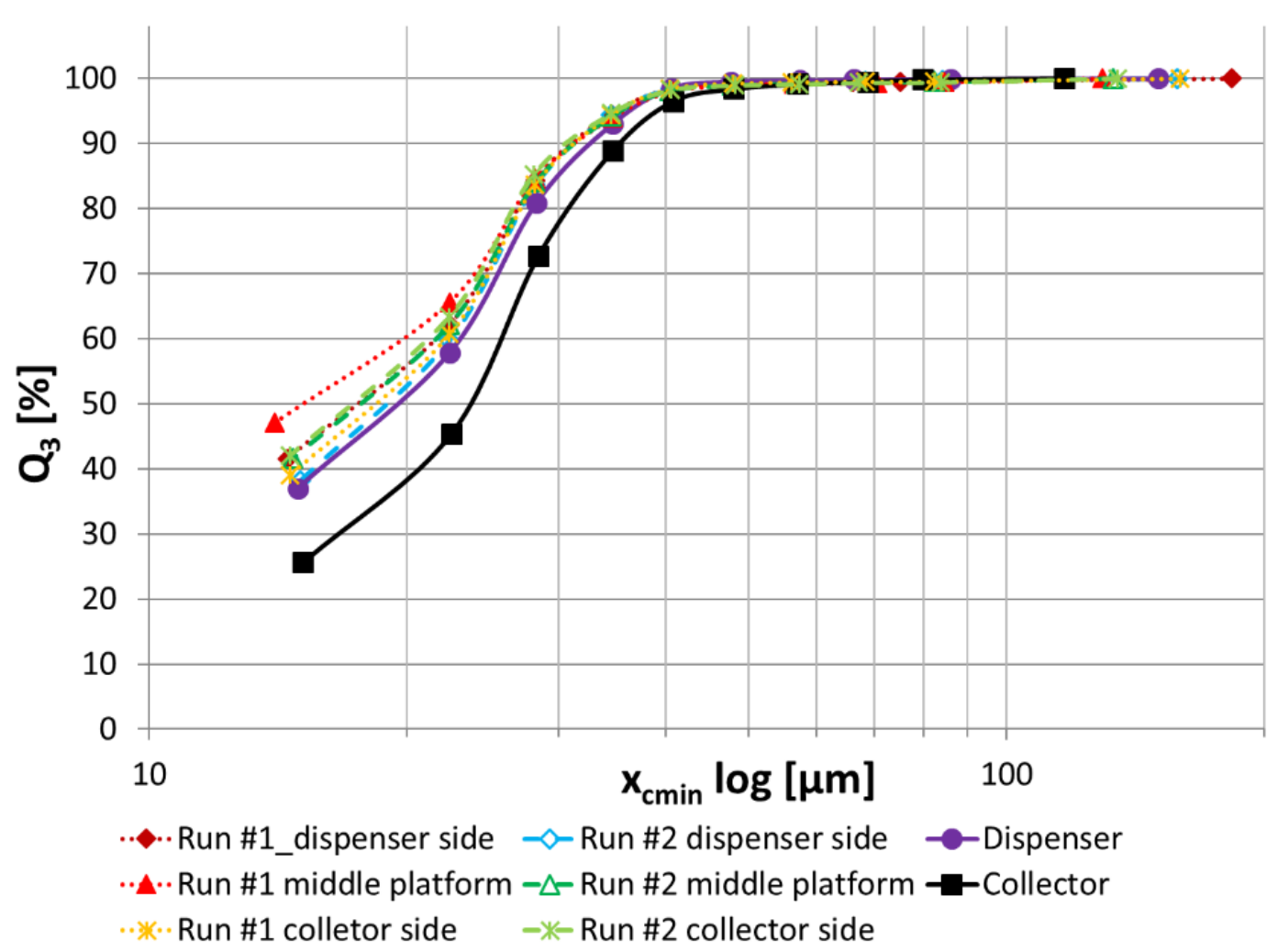

Figure 12. Particle size cumulative distribution $\left(\mathrm{Q}_{3}\right)$ of IN625 powder samples from different locations along the recoater blade motion.

Although Figure 12 indicates that, except for the collector bin, PSDs from various locations have similar characteristics, a closer look in Figure 13 shows that the particle sizes increase slightly along the recoater blade direction. This observation can be better quantified with the $\mathrm{D}_{90} / \mathrm{D}_{10}$ ratio. $\mathrm{D}_{90} / \mathrm{D}_{10}$ ratios are between 3.2 and 2.7. The decreasing ratio in the direction of the recoater blade motion may be the result of a narrower powder size distribution due to two changes: less smaller particles, and more larger particles across the build platform. First, the powder in front of the recoater blade may be depleted of finer particles, because these particles form the powder layer closer to the dispenser bin. Second, remaining coarser particles were pushed across by the recoater blade into the collector bin. It is assumed that only powder particles in the same size range of the actual layer thickness, i.e., effective layer thickness (teff-n), can form the powder layer either on the prior solidified part surface or on the top surface of the loose powder bed. Particles which are bigger than teff.-n will be simply "snowplowed" across the powder bed on the build platform by the recoater blade into the collector bin. This may explain the accumulation of coarser particles observed in the collector bin.

The virgin S17-4 powder has a lower amount of the finer particle proportion $\left(q_{3} \leq 20 \mu \mathrm{m}\right)$ than the IN625 powder. Figure 14 shows that the amount of this finer powder fraction $\left(q_{3} \leq 20 \mu \mathrm{m}\right)$ is less than $5 \%$, in contrast to the IN625 powder that has about $35 \%$ of the same fine particle size fraction. Particles bigger than $60 \mu \mathrm{m}$ are less than $5 \%$ of the bulk powder. Hence, D90 is less than $60 \mu \mathrm{m}$. 


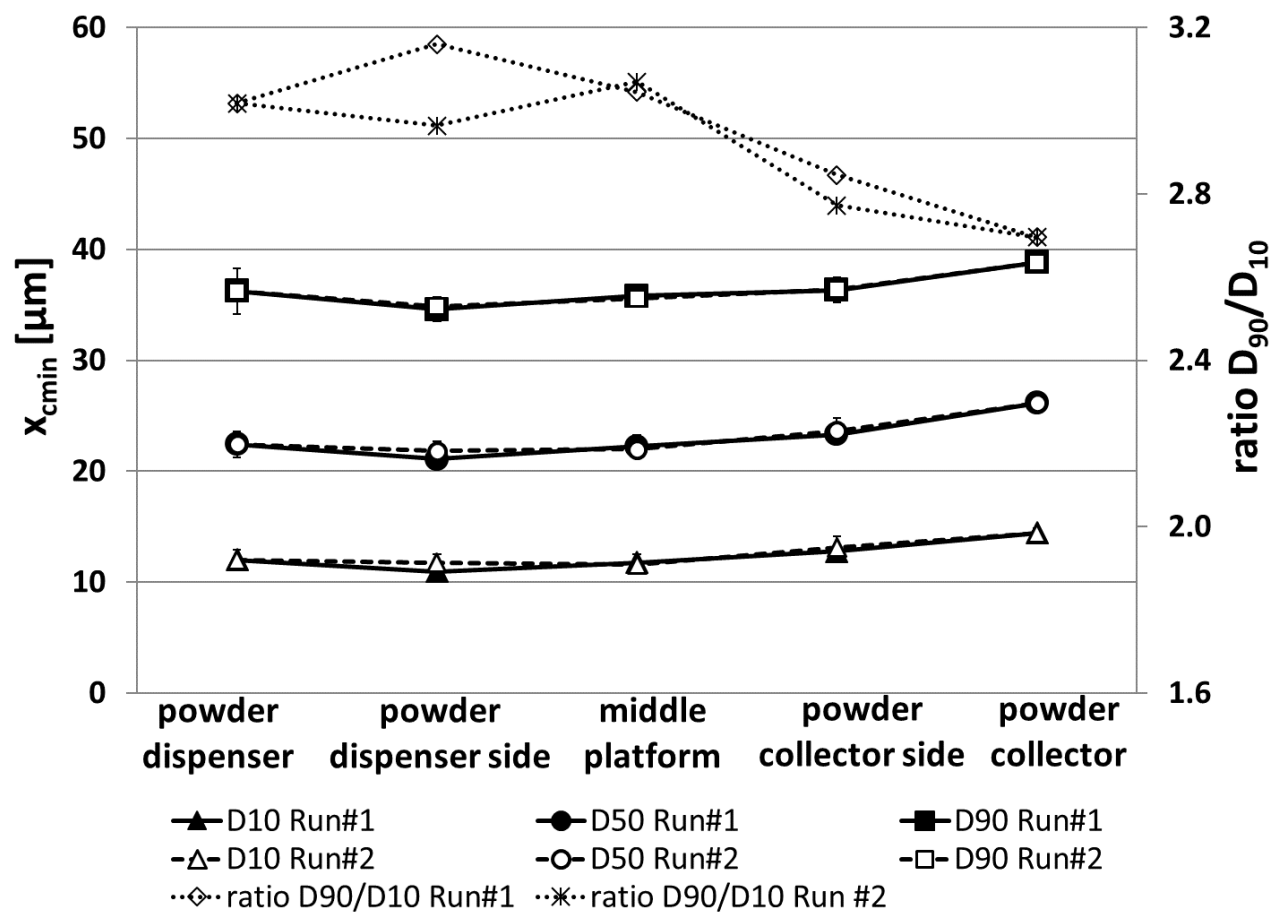

Figure 13. Particle size of IN625 powder samples from different locations along recoater blade motion, averages of $\mathrm{D}_{10}, \mathrm{D}_{50}$, and $\mathrm{D}_{90}$ (error bars show the standard deviation).

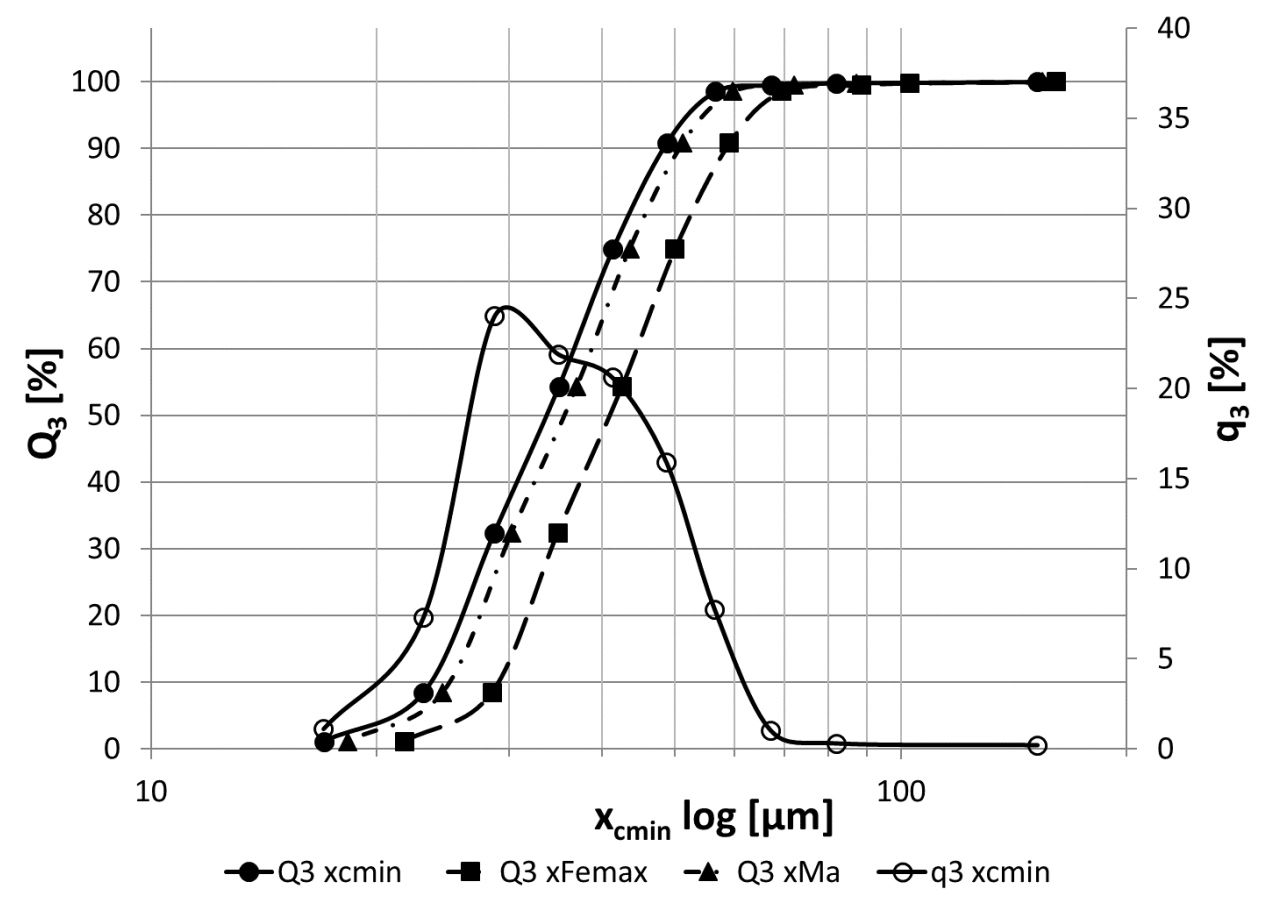

Figure 14. Particle size frequency distribution ( $\left.\mathrm{q}_{3}\right)$ for $\mathrm{x}_{\mathrm{cmin}}$, and particle size cumulative distribution $\left(\mathrm{Q}_{3}\right)$ for $\mathrm{x}_{\mathrm{Cmin}}, \mathrm{X}_{\mathrm{Femax}}$, and $\mathrm{x}_{\mathrm{Ma}}$ of $\mathrm{S} 17-4$ powder from dispenser bin. 
The measured values of $\mathrm{D}_{10}, \mathrm{D}_{50}$, and $\mathrm{D}_{90}$ for $\mathrm{S} 17-4$ powders from different locations on the build platform for run \#1 and \#2 are presented in Table 6, Figure 15, and Figure 16. PS and PSD of the S17-4 powder show a similar trend as observed previously for IN625 powder where coarser particles appear to be "snowplowed" across the powder bed and into the collector bin. However, the particle size increases along the recoater blade motion for IN625 powder was not observed for the virgin S17-4 powder from run \#1.

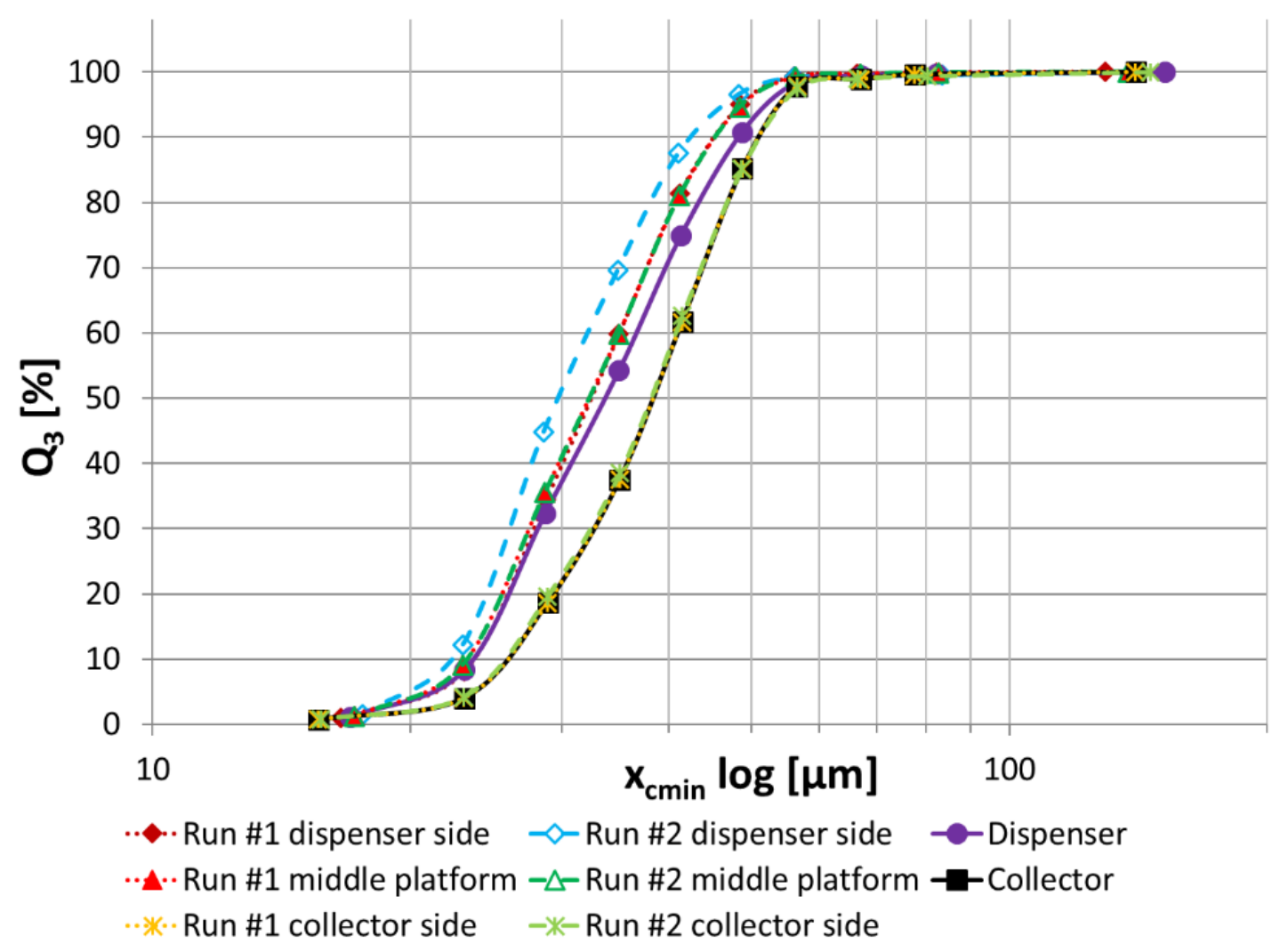

Figure 15. Particle size cumulative distribution $\left(\mathrm{Q}_{3}\right)$ of $\mathrm{S} 17-4$ powder samples from different locations along the recoater blade motion. 
Table 6. Particle sizes $\left(\mathrm{D}_{10}, \mathrm{D}_{50}\right.$, and $\left.\mathrm{D}_{90}\right)$ of S17-4 powder samples from different locations along the direction of the recoater blade motion. Average (AVE) and one standard deviation (STDEV.S) values are calculated from a total of 18 measurements (3 powder samples repeatedly measured 6 times).

\begin{tabular}{lcccccccc}
\hline $\begin{array}{l}\text { S17-4 powder } \\
\text { samples }\end{array}$ & $\begin{array}{c}\text { AVE } \\
{[\mu \mathrm{m}]}\end{array}$ & $\begin{array}{c}\text { STDEV.S } \\
{[\mu \mathrm{m}]}\end{array}$ & $\begin{array}{c}\text { AVE } \\
{[\mu \mathrm{m}]}\end{array}$ & $\begin{array}{c}\text { STDEV.S } \\
{[\mu \mathrm{m}]}\end{array}$ & $\begin{array}{c}\text { AVE } \\
{[\mu \mathrm{m}]}\end{array}$ & $\begin{array}{c}\text { STDEV.S } \\
{[\mu \mathrm{m}]}\end{array}$ & $\begin{array}{c}\text { Ratio } \\
D_{90} / \mathrm{D}_{10}\end{array}$ & SPAN \\
\hline Run \#1 - virgin powder & & & & & & & & \\
Dispenser bin & 25.4 & 0.9 & 36.4 & 1.8 & 51.8 & 1.8 & 2.0 & 0.7 \\
Dispenser side (1.x) & 25.3 & 0.5 & 34.9 & 0.7 & 49.1 & 0.7 & 1.9 & 0.7 \\
Middle platform (2.x) & 24.6 & 0.7 & 33.8 & 1.4 & 47.9 & 2.2 & 2.0 & 0.7 \\
Collector side (3.x) & 24.2 & 0.5 & 33.2 & 0.9 & 47.3 & 1.2 & 2.0 & 0.7 \\
Collector bin & 27.4 & 1.7 & 39.9 & 2.4 & 54.3 & 1.4 & 2.0 & 0.7 \\
\hline Run \#2 - once recycled powder & & & & & & & \\
Dispenser side (1.x) & 24.6 & 0.3 & 33.6 & 0.6 & 47.8 & 1.5 & 1.9 & 0.7 \\
Middle platform (2.x) & 24.4 & 0.1 & 33.3 & 0.2 & 47.4 & 0.8 & 2.0 & 0.7 \\
Collector side (3.x) & 25.9 & 0.2 & 36.2 & 0.3 & 50.6 & 0.4 & 2.0 & 0.7 \\
Collector bin & 27.9 & 0.4 & 40.8 & 0.6 & 55.4 & 0.5 & 2.0 & 0.7 \\
\hline
\end{tabular}

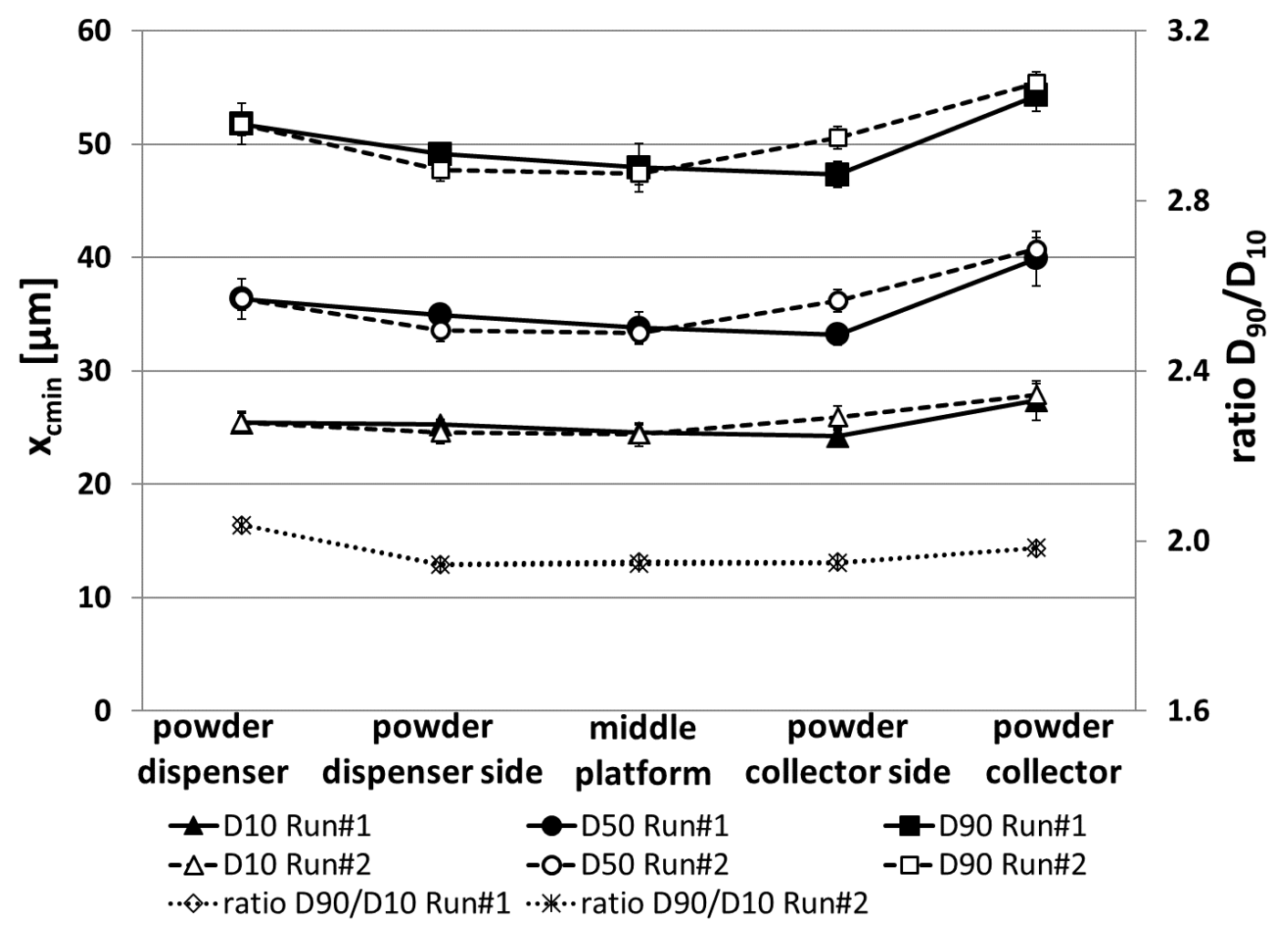

Figure 16. Particle size of S17-4 powder samples from different locations along the direction of the recoater blade motion, averages of $\mathrm{D}_{10}, \mathrm{D}_{50}$, and $\mathrm{D}_{90}$ (error bars show the standard deviation). 
The once-recycled S17-4 powder (used for run \#2) shows a slight increase in measured particle sizes, especially on the build plate-collector side. This may be the result of recycled powder after run \#1 that was enriched with coarser particles, which pass through the $80 \mu \mathrm{m}$ sieve used to sieve the collected powder after run \#1 before using it for run \#2. Such coarser particles tend to accumulate more towards the collector side of the build platform due to the previously mentioned layer forming mechanism using smaller particles first.

The obtained $\mathrm{D}_{90} / \mathrm{D}_{10}$ ratios for powders from the build platform are between 2.0 to 1.9 regardless of their location, while the $\mathrm{D}_{90} / \mathrm{D}_{10}$ is between 3.2 and 2.7 for IN625 powder. Although the SPAN parameter for S17-4 powder is smaller $(0.7)$ than for IN625 $(\approx 1)$, the S17-4 powder shows a wider PSD (peak width) and a larger amount of the size fraction $30 \mu \mathrm{m} \leq \mathrm{x}_{\mathrm{cmin}} \leq 60 \mu \mathrm{m}$ than the IN625 powder (compare $\mathrm{q}_{3}$ in Figure 11 and Figure 14), which is represented by the higher $\mathrm{D}_{50}$ sizes. These differences in the PSDs may explain the different powder deposition and the higher relative PBD of S17-4 powder ( $\approx 60 \%$ of bulk material density) to IN625 powder ( $\approx 56 \%$ of bulk material density).

It appears that the effect of the PSD on the powder bed density in a LPBF machine, with a fixed recoater blade system, is similar to the effect on the bulk powder apparent density as observed by Nolan and Kavanagh [5]. Like the IN625 powder, coarser particles of S17-4 powder were pushed across the build platform into the collector bin, as shown in Figure 14 for both build runs. These findings correspond to the results published by Liu et al. [9]. They showed that a wider range of the particle sizes in a metal powder for Selective Laser Melting (SLM) processes can create a powder bed with a higher density, because smaller particles can fill the gaps between larger particles [9]. Our results are consistent with theirs where the S17-4 powder with a larger size distribution leads to a higher relative PBD than the IN625 powder.

\subsection{Particle Segregation Behavior During Powder Spreading}

It is important to note that spreading powder with a rigid recoater blade generates the typical "front stress-free turning powder wedge behavior" described by Amado et al. [18]. A powder with a polydisperse PSD segregates when particles are in motion. This segregation leads smaller particles to migrate towards the bottom of the bulk powder while coarser particles form the upper powder proportion. This behavior may be the reason for the segregation of different powder particle sizes while the powder is pushed across the build platform as measured in our study.

Figure 17 to Figure 20 show schematically the powder deposition across the build platform and the effect of the stress-free turning powder wedge behavior on the particle size segregation. These figures illustrate the assumption applied to the LBPF system that finer particles of the bulk powder in front of the moving recoater blade segregate at the bottom of the pushed powder wave and tend to accumulate in the powder bed near the dispenser side. While the powder wave moves over the loose powder bed or the solidified part surface, as the recoater blade moves toward the collector bin, the number 
of finer particles will be reduced and coarser particles will form the powder bed or layer. This assumption that coarser particles preferentially form the powder bed and powder layer as the recoater blade moves further across the build platform could not be verified in this work, but results of the particle size measurements (see Figure 13 and Figure 16) show an obvious increase in the particle size of the powder from the collector bin.

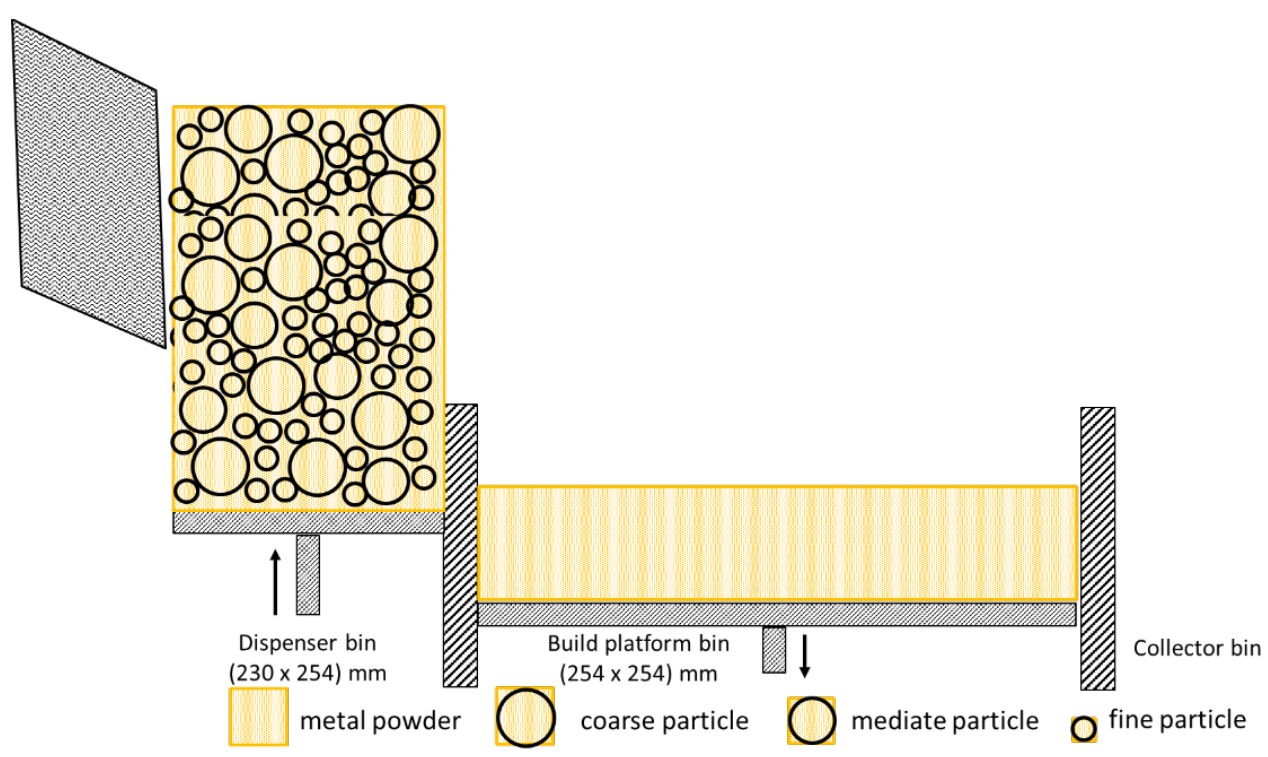

Figure 17. The system prepares for powder deposition by moving the dispenser bin and build platform to set the powder amount per the charge factor.

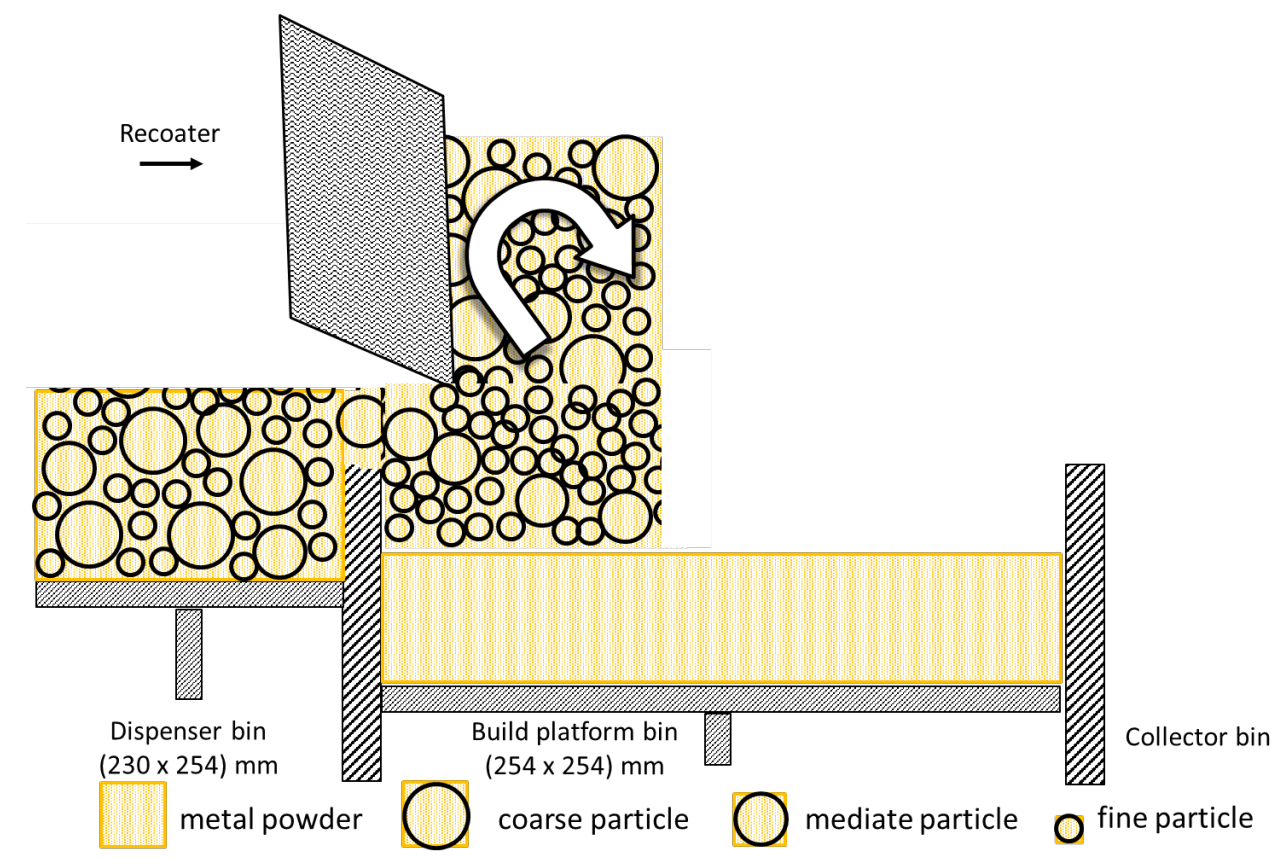

Figure 18. Powder deposition begins as the recoater blade moves the powder wave over the lowered build platform at the dispenser side. The motion causes smaller sized particles to move downward towards the powder bed. 


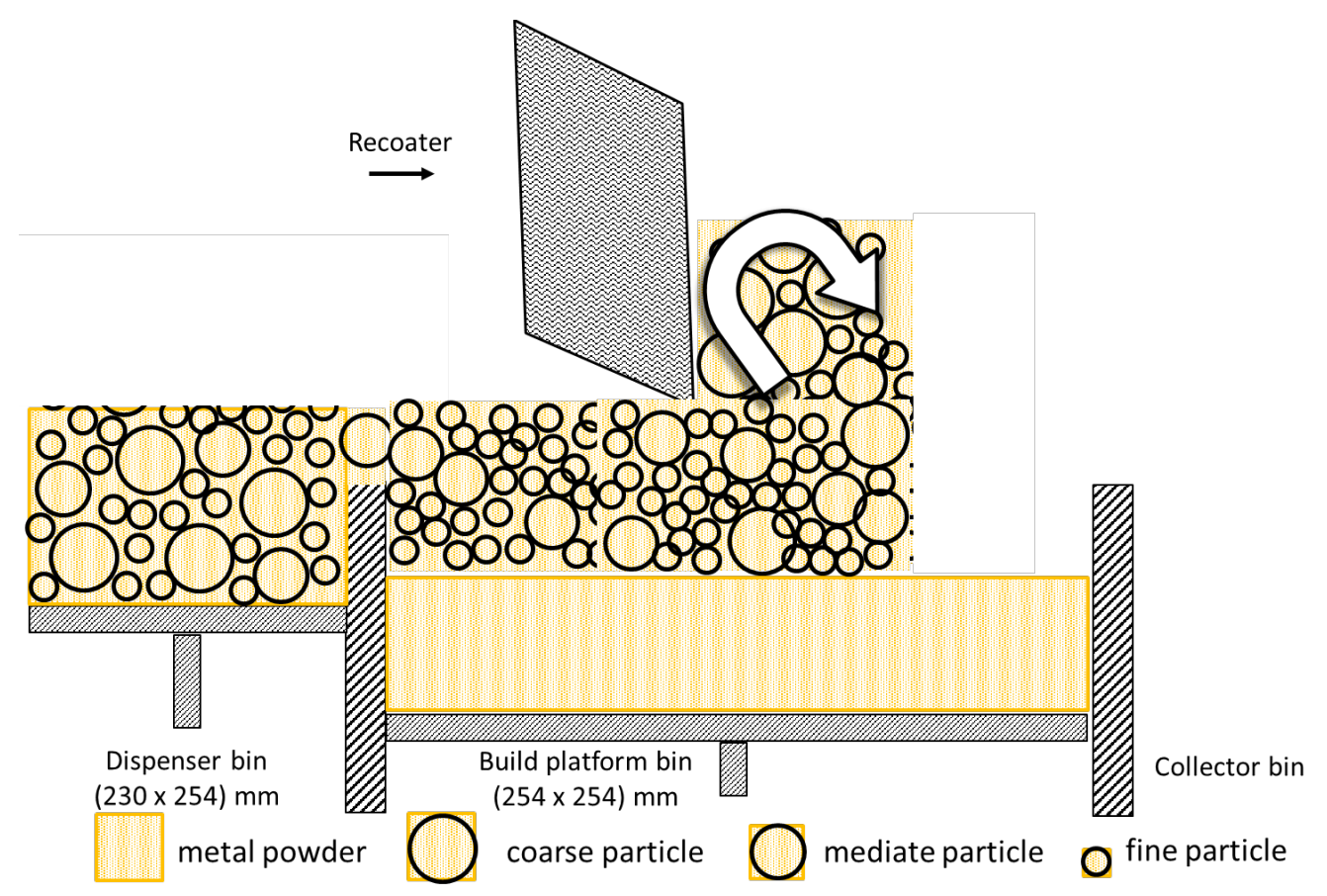

Figure 19. Powder deposition continues as the recoater blade moves the powder wave over the middle of the lowered build platform. The motion continues to cause smaller sized particles to move downward towards the powder bed.

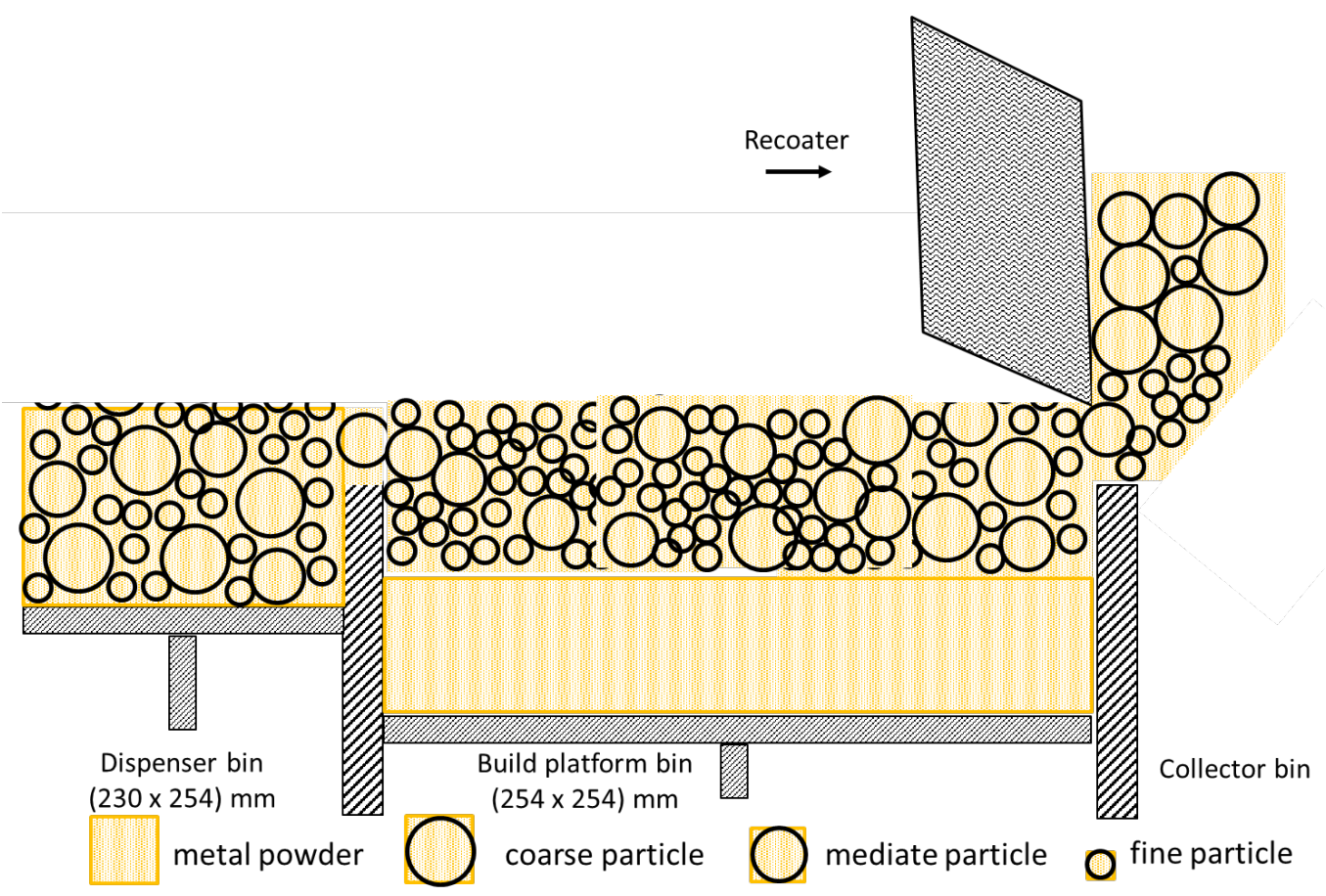

Figure 20. Powder deposition finishes as the recoater blade moves the remaining powder wave into the collector bin. The remaining powder fraction at this end of the build platform and in the collector bin consists of remaining larger particles. 


\subsection{Effective Layer Thickness}

The nominal layer thickness is the incremental step the build platform lowers to create a gap between the recoater blade and the top surface of the previous layer. Moving the recoater blade, with a specified volume of powder in front, fills this gap with a new powder layer. The real layer thickness is greater than the incremental step because the solidification process causes the top surface of the previous layer to shrink or contract.

The effective layer thickness is determined by calculating the shrinkage of the material due to the melting and solidification process. The shrinkage is proportional to the relative powder layer density with respect to the bulk material density. For example, if the powder layer density (PLD) is $60 \%$ of the bulk material density, for a $20 \mu \mathrm{m}$ thick powder layer, the height of the shrinkage would be about $8 \mu \mathrm{m}$. Therefore, the effective layer thickness for the next layer will be $28 \mu \mathrm{m}$. Assuming PLD is approximately the same as the PBD, Equations 2 to 4 show how teff. $n+1$ of a certain powder layer number (n) is computed [8].

$$
t_{\text {eff. } n+1}=t_{\text {eff.-n }}+\left(t_{\text {shrink. }-n}-t_{\text {shrink. } n-1}\right)
$$

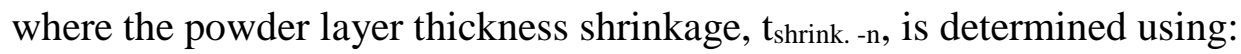

$$
t_{\text {shrink.-n }}=t_{\text {eff. }-n} \cdot V_{\text {voids }}
$$

and volume fraction of voids, $\mathrm{V}_{\text {voids, }}$, are determined using relative $\mathrm{PBD}$, ( $\left.\mathrm{PBD}_{\text {relative}}\right)$, which is the PBD divided by the bulk material density:

$$
V_{\text {voids }}=1-P B D_{\text {relative }}[\%]
$$

We compared the results of this study with the derived criteria by Spierings et al. [8] that suggests $t_{\text {eff.-n }}$ to be about $50 \%$ greater than $\mathrm{D}_{90}$ and $\mathrm{D}_{90}$ shall be five times greater than $\mathrm{D}_{10}$. Figure 21 shows the computed teff.-n based on the mean PBD for IN625 (Table 3) and S17-4 (Table 4), for run \#1 and run \#2 using Equation 4.

Figure 21 shows that after twelve layers ( $\mathrm{t}_{\text {eff.-12) }}$ ) the calculated effective layer thickness reaches a constant value depending on the mean PBD. The higher relative PBD (of approximately $60 \%$ ) for the S17-4 powder leads to a smaller teff-12 (about $33 \mu \mathrm{m}$ ). The lower relative PBD of approximately $56 \%$, for the IN625 powder has a $t_{\text {eff.-12 }}$ of about $35.7 \mu \mathrm{m}$. 


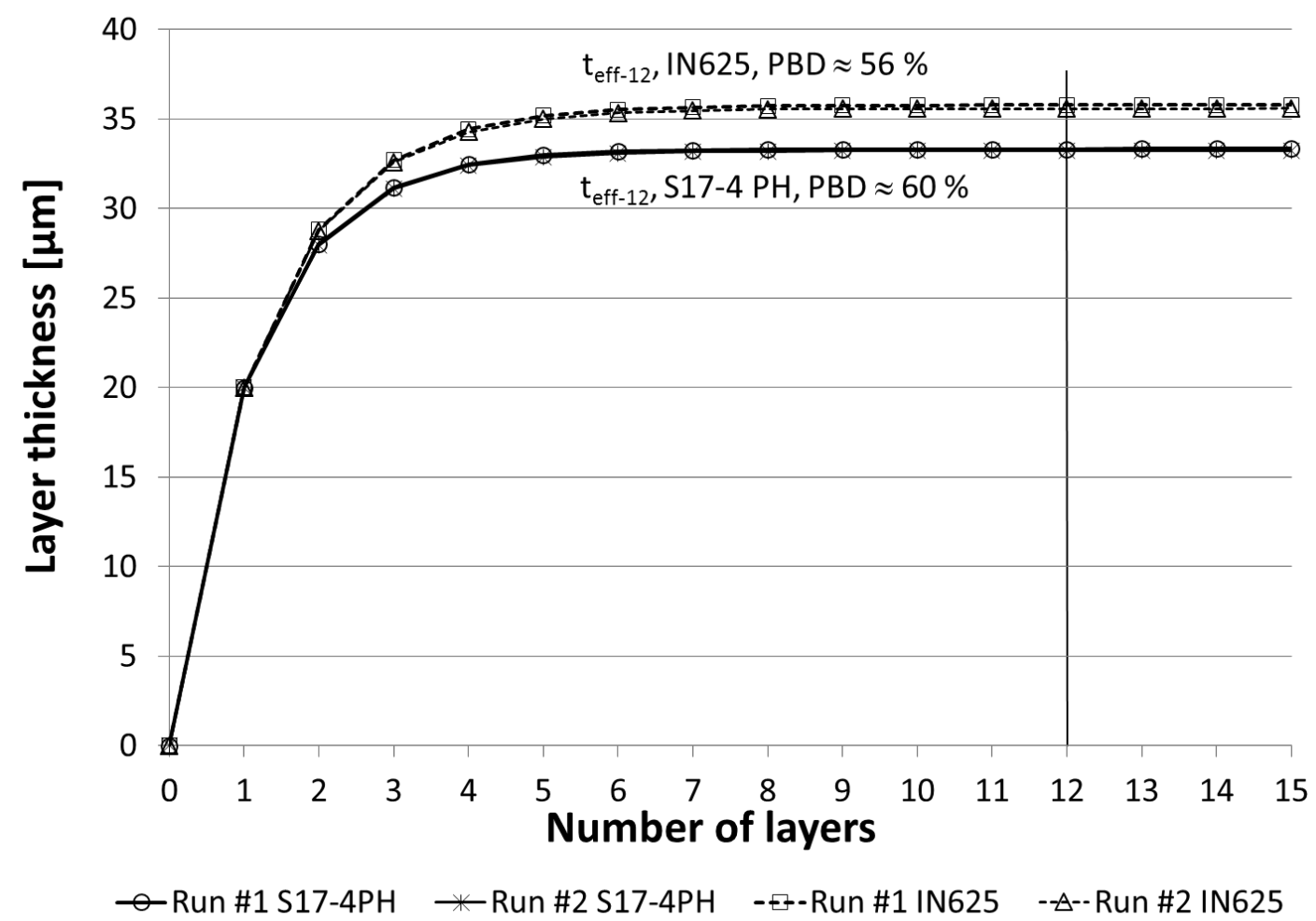

Figure 21. Calculated effective layer thickness of virgin and once-recycled S17-4 and IN625 powder.

Results of the particle size measurement for both IN625 and S17-4 powders were previously presented in Table 5 and Table 6, respectively. Based on the $D_{90}$ values of powder samples from the dispenser bin and $t_{\text {eff.-12 }}$, the ratio of $t_{\text {eff.-12 }} / \mathrm{D}_{90}$ were computed to assess which powder particle size fractions formed the powder layers. A teff.-12 / $\mathrm{D}_{90}$ ratio of less than 1 indicates that all particles equal or bigger than $\mathrm{D}_{90}$ were not in the powder layer and hence, these were pushed across the build platform by the recoater blade into the collector bin. The teff.-12 / D90 ratio for IN625 shows values (see Table 7) close to 1 indicating that a layer thickness was reached that even particles with a size around the $\mathrm{D}_{90}$ value were able to fit between the solidified part top surface and the passing recoater blade. This assumption corresponds with the previous results of the particle size measurements (see Table 5), which show that the D90 values of powder samples from all locations on the build platform are in the range of teff.-12. Therefore, it can be assumed that particles of almost all size fractions from a $\mathrm{D}_{10}$ of approximately $11 \mu \mathrm{m}\left(\mathrm{x}_{\mathrm{cmin}}\right)$ to a $\mathrm{D}_{90}$ of approximately $36.4 \mu \mathrm{m}$ (see Table 5) could form the powder layer.

In contrast, the S17-4 powder had higher amounts of coarser particles $\left(\mathrm{D}_{90}=47.3 \mu \mathrm{m}\right.$ to $50.5 \mu \mathrm{m}$ ), as shown in Figure 14. Comparing these numbers with teff.-12, it can be assumed that not all particles from all size fractions could form the powder layer, represented by teff.-12 / $\mathrm{D}_{90}$ ratios of 0.66 to 0.70 (see Table 7). 
Table 7. Computed ratio of teff.-n and $\mathrm{D}_{90}$ for virgin and once recycled IN625 and S17-4 powder.

\begin{tabular}{lcc|cc}
\hline Material & \multicolumn{2}{c|}{ IN625 powder samples } & \multicolumn{2}{c}{ S17-4 powder samples } \\
\hline Ratio & $\begin{array}{c}\text { Build Run \#1 } \\
\text { virgin powder }\end{array}$ & $\begin{array}{c}\text { Build Run \#2 } \\
\text { virgin powder }\end{array}$ & $\begin{array}{c}\text { Build Run \#1 } \\
\text { virgin powder }\end{array}$ & $\begin{array}{c}\text { Build Run \#2 } \\
\text { once recycled powder }\end{array}$ \\
$\mathbf{t}_{\text {eff.-12 / D90 }}$ & 0.99 & --- & 0.64 & --- \\
\hline Dispenser bin & 1.03 & 1.02 & 0.68 & 0.70 \\
Dispenser side (1.x) & 1.00 & 1.00 & 0.69 & 0.70 \\
Middle platform (2.x) & 0.99 & 0.98 & 0.70 & 0.66 \\
Collector side (3.x) & 0.92 & 0.92 & 0.61 & 0.60 \\
Collector bin & & & & \\
\hline
\end{tabular}

Although, particles bigger than teff--12 could not form the powder layer and the bulk S17-4 powder shows a low amount (less than $5 \%$ ) of the particle size fraction $\mathrm{x}_{\mathrm{cmin}} \leq 20 \mu \mathrm{m}$, a higher relative PBD was obtained in comparison to the IN625 powder. A reason for this behavior could be, as previously shown in Figure 14, the wider PSD and higher amount of the size fraction $30 \mu \mathrm{m} \leq \mathrm{x}_{\mathrm{cmin}} \leq 60 \mu \mathrm{m}$ for the S17-4 than in the IN625 powder. Apparently, the size fraction of $30 \mu \mathrm{m} \leq \mathrm{x}_{\mathrm{cmin}} \leq 60 \mu \mathrm{m}$ for the amount used in this study, helps to form a dense powder bed in a LPBF machine with $20 \mu \mathrm{m}$ incremental moving steps of the build platform (nominal layer thickness). These results are consistent with those from Slotwinski et al. [19]. They showed that the recoater blade was preferentially transporting larger particles $(>60 \mu \mathrm{m})$ past the build plate. Results of this work are consistent with the results presented by Spierings et al. [8], where an assumed smaller teff.-n was obtained as a higher tap density of the powder was considered. The relative tap densities for three different 316L stainless steel powders were in a range from approximately $57.6 \%$ to $60.1 \%$ [8]. This is very interesting because the mean PBD values for both metal powders in this study were approximately $56 \%$ for IN625 and approximately $60 \%$ for S17-4, which are in the range of the relative tap density as presented by Spierings et al. [8]. Hence, the deposition of metal powders with similar characteristics in particle size and particle shape as presented in this study and investigated by Spierings et al. [8] lead to a PBD that is very close to the apparent density measured with the Hall funnel flowmeter [13] (see results in section 4.1) and the tap density presented by Spierings et al. [8].

\section{Conclusions}

This study investigated the changes in the bulk powder properties caused by spreading with a rigid recoater blade on the build platform. Two types of powder (IN625 and S174) with different PSDs and densities were used in the study. The following conclusions were reached.

AD was found to be similar to PBD for the IN625 powder but not as similar for the S17-4 powder as determined by the ratio of $\mathrm{PBD} / \mathrm{AD}$. The average PBD was less affected by changing the powder conditions (particle size and PSD) when compared to AD. 
Although not by a significant amount, the PBD for the IN625 powder tended to decrease along the recoater blade direction while the PBD for S17-4 tended to increase slightly.

PBD increased slightly, but not significantly, from run \#1 to run \#2 for both powders. The increase in PBD for run \#2 for the S17-4 powder was likely due to a minor effect of the once-recycled powder on the PBD, the accumulation of bigger particles $\leq 80 \mu \mathrm{m}$ after recycling the powder one time.

The relative PBD was $56 \%$ of bulk material density for IN625 and $60 \%$ of bulk material density for S17-4. The IN625 powder was generally smaller with a narrower PSD while S17-4 was generally larger with a wider PSD. The larger relative PBD for S17-4 was expected as we assume that the smaller powder particles were able to fit between the coarser particles resulting in an increased relative PBD.

Although not significant, particle size slightly increased along the recoater blade direction for IN625 and no trend was observed for the S17-4 except for the once-recycled powder for run \#2 that tended to show an increase in powder size towards the collector side of the build plate. These results show that there is a slight relationship between the particle size that forms the powder layer and build plate location. When the solidified part surface is underneath the powder layer, it may prevent particles bigger than the layer thickness to be pressed into the powder layer. Only powder with a smaller or equal particle size that can fit in the gap between the part surface and the recoater blade can form the powder layer. This specific portion may have a narrower PSD compared to the portion which may form the powder bed but not above a part surface.

The calculated effective layer thickness was shown to reach an equilibrium at a smaller effective layer thickness for the S17-4 powder with the higher relative PBD. The IN625 powder had a larger effective layer thickness with a lower relative PBD.

Users can assess the PBF process and part quality, and take actions in making changes to their build parameter settings (e.g., recoater charge factor), choice of powder material (e.g., PSD), or design and arrangement of parts on a build platform in a PBF machine. Further study is needed to determine and quantify the effect of varying PSDs of metal powders, changing machine settings like nominal layer thickness and the recoater charge factor, the effects of solidified layers, as well as changing the design and material of the recoater blade to determine their impact on the PBD in PBF machine systems.

\section{Acknowledgment}

The authors would like to acknowledge the contributions by John Slotwinski, $\mathrm{PhD}$, Stephanie Watson, $\mathrm{PhD}$, and Edward J. Garboczi, PhD, because without their valuable assistance and their knowledge in powder characterization methods and suitability of these methods for AM processes, this presented work would not have been possible. 


\section{References}

[1] Jacob G, Donmez A, Slotwinski J, Moylan S (2016) Measurement of powder bed density in powder bed fusion additive manufacturing processes, Journal of Measurement Science and Technology, Vol 27.

[2] McGeary RM (1961) Mechanical Packing of Spherical Particles. Journal of the American Ceramic Society, 44(10):513-522.

[3] German RM (1984) Powder Metallurgy Science, Metal Powder Industries Federation, Princeton, NJ.

[4] Zok F, Lange FF, Porter JR (1991) Packing Density of Composite Powder Mixtures. Journal of the American Ceramic Society, 74(8):1880-1885.

[5] Nolan GT, Kavanagh, PE (1994) The size distribution of interstices in random packing spheres. Powder Technology 78:231-238.

[6] Karapatis NP, Egger G, Gygax PE, Glardon R (1999) Optimization of Powder Layer Density in Selective Laser Sintering. Proceedings of the Solid Freeform Fabrication Symposium, Austin, TX, 255-263.

[7] Zhu HH, Fuh JYH, and Lu L (2006) The influence of powder density on the density in direct laser-sintered metallic parts. International Journal of Machine Tools \& Manufacture, 47:294-298.

[8] Spierings AB, Levy G (2009) Comparison of density of stainless steel 316L parts produced with selective laser melting using different powder grades. Proceedings of the Solid Freeform Fabrication Symposium, Austin, TX, 342-353.

[9] Liu B, Wildman R, Tuck C, Ashcroft I, Hague R (2011) Investigation the Effect of Particle Size Distribution on Processing Parameters Optimization in Selective Laser Melting Process. Proceedings of the Solid Freeform Fabrication Symposium, Austin, TX, 227-238.

[10] Carpenter Powder Products (2013) Powder certificate for Micro-Melt 625AM, LOT: W1856B2, Carpenter Powder Products Inc., Bridgeville, PA.

[11] EOS (2013) Mill Specification for SS 17-4 PH, LOT: F171001, Electro Optical Systems EOS GmbH, Krailling, Germany.

[12] ASTM International (2015) ASTM B215 Standard Practices for Sampling Metal Powders, ASTM International, West Conshohocken, PA.

[13] ASTM International (2009) ASTM B212 Standard Test Method for Apparent Density of Free-Flowing Metal Powders Using the Hall Flowmeter Funnel, ASTM International, West Conshohocken, PA. 
[14] International Organization for Standardization (2006) ISO 13322-2; Particle size analysis - Image analysis methods -- Part 2: Dynamic image analysis methods, International Organization for Standardization, Geneva, Switzerland.

[15] International Organization for Standardization (1998) ISO 9276-1: Representation of results of particle size analysis - Part 1: Graphical representation, International Organization for Standardization, Geneva, Switzerland.

[16] Retsch Technology (2013) Installation and Operating Manual for Particle Size Analysis System CAMSIZER, Retsch Technology GmbH, Haan, Germany.

[17] Jacob G, Brown C, Donmez A, Watson S, Slotwinski J (2017) Effects of powder recycling on stainless steel powder and built material properties in metal powder bed fusion processes. NIST Advanced Manufacturing Series 100-6. doi.org/10.6028/NIST.AMS.100-6.

[18] Amado A, Schmidt M, Levy G, Wegner K (2011) Advances in SLS powder characterization. Proceedings of the Solid Freeform Fabrication Symposium, Austin, TX, 438-452.

[19] Slotwinski JA, Garboczi EJ, Stutzman PE, Ferraris CF, Watson SS, Peltz MA (2014) Characterization of Metal Powders Used for Additive Manufacturing. Journal of Research, National Institute of Standards and Technology, Vol. 11. doi.org/10.6028/jres.119.018. 